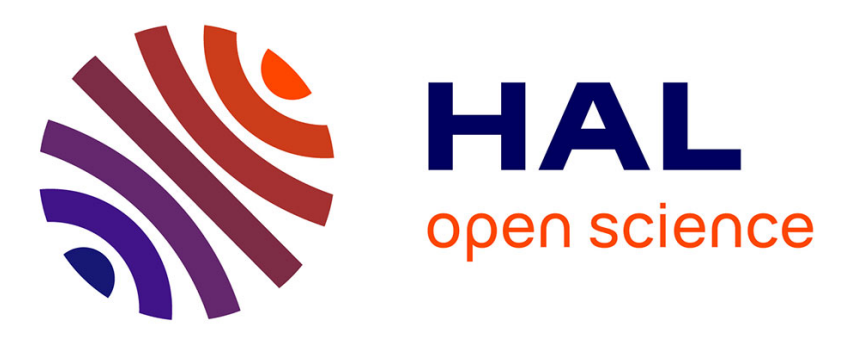

\title{
Ensilage et artisanat du fer entre le Hallstatt D3 et La Tène ancienne à Weyersheim (Bas-Rhin). Premiers résultats
}

Matthieu Michler, Sylvain Badey, Marion Berranger, Luisella Cabboï, Patrick Clerc, Florent Jodry, Olivier Putelat, Marieke van Es

\section{To cite this version:}

Matthieu Michler, Sylvain Badey, Marion Berranger, Luisella Cabboï, Patrick Clerc, et al.. Ensilage et artisanat du fer entre le Hallstatt D3 et La Tène ancienne à Weyersheim (Bas-Rhin). Premiers résultats. Archimède: archéologie et histoire ancienne, 2018, Archimède ${ }^{\circ} 5$. Archéologie et histoire ancienne, 5, pp.202-229. halshs-01826474

\section{HAL Id: halshs-01826474 \\ https://shs.hal.science/halshs-01826474}

Submitted on 29 Jun 2018

HAL is a multi-disciplinary open access archive for the deposit and dissemination of scientific research documents, whether they are published or not. The documents may come from teaching and research institutions in France or abroad, or from public or private research centers.
L'archive ouverte pluridisciplinaire HAL, est destinée au dépôt et à la diffusion de documents scientifiques de niveau recherche, publiés ou non, émanant des établissements d'enseignement et de recherche français ou étrangers, des laboratoires publics ou privés. 


\section{ARCHIMĖDE N N 5

1 DOSSIER THÉMATIQUE : HUMOEROTICA

108 ACTUALITÉ DE LA RECHERCHE : DES FEMMES PUBLIQUES. GENRE, VISIBILITÉ ET SOCIABILITÉ DANS L'ANTIQUITÉ GRECQUE ET ROMAINE

\section{VARIA}

185 Daniela LEFÈVRE-NOVARO

Phaistos, Dréros, Praisos : monuments publics et naissance de la polis en Crète

202 Matthieu MICHLER avec la collaboration de Sylvain BADEY, Marion BERRANGER, Luisella CABBOÏ, Patrick CLERC, Florent JODRY, Olivier PUTELAT et Marieke VAN ES Ensilage et artisanat du fer entre le Hallstatt D3 et La Tène ancienne à Weyersheim (Bas-Rhin). Premiers résultats

230 Gael CARTRON, Bertrand ROSEAU et Julien BRUYÈRE

Le territoire de Warcq à l'époque romaine : résultats de six fouilles préventives (2012-2017) menées dans la partie nord du département des Ardennes, près de Charleville-Mézières 


\section{ENSILAGE ET ARTISANAT DU FER \\ ENTRE LE HALLSTATT D3 ET LA TĖNE ANCIENNE \\ À WEYERSHEIM (BAS-RHIN). \\ PREMIERS RÉSULTATS}

Matthieu MICHLER

Chargé d'études et d'opérations

\section{Sylvain BADEY}

Technicien d'opération - Archéomaticien, Inrap, UMR7324 CITERES Laboratoire Archéologie et Territoires sylvain.badey@inrap.fr

\section{Marion BERRANGER}

Ingénieure de recherche CNRS - Archéométallurgiste, UMR 5060 IRAMAT Belfort

marion.berranger@utbm.fr

\section{Luisella CABBOÏ}

Chargé d'études et d'opérations, Inrap, UMR 5060 IRAMAT Belfort

luisella.cabboi@inrap.fr

\section{Patrick CLERC}

Responsable d'opération, Inrap, UMR 5060 IRAMAT Belfort patrick.clerc@inrap.fr

\section{Florent JODRY}

Responsable d'opération, macrolithicien, Inrap, UMR 7044 Archimède

florent.jodry@inrap.fr

\section{Olivier PUTELAT}

Archéo-zoologue, Archéologie Alsace, UMR 7041 ArScAn « Archéologies Environnementales » Université de Paris 1 Panthéon-Sorbonne / MAE Nanterre

olivier.putelat@archeologie.alsace

\section{Marieke van ES}

Céramologue, Inrap

marieke.van-es@inrap.fr 


\section{RÉSUMÉ}

Le site de Weyersheim «Les Hauts de la Zorn » (Bas-Rhin), fouillé en 2014 par I'Inrap a livré pour la première fois en Alsace les restes d'un atelier de forge, sur un site occupé de la fin du Hallstatt au début de La Tène ancienne.

Outre la mise au jour de nombreux silos, ayant livré des artefacts céramiques et métalliques typiques, deux structures (silo 1003 et fosse 1014) situées au sud-ouest de l'emprise, se singularisent par la quantité impressionnante de déchets métallurgiques découverte (110 kg de scories incluant près de 280 culots). L'analyse de ces déchets a mis en évidence un travail de post-réduction, depuis l'épuration du métal brut à la mise en forme d'objet.

Des outils lithiques, ainsi

\section{Mots-CLÉs}

Âge du Fer,

habitat,

Alsace,

production,

fer,

forge,

enclumes,

outils lithiques, scories. qu'un important lot d'enclumes en granite ont également été mis au jour.

Cette découverte atypique permet de nous interroger sur la place de la métallurgie en Alsace au ve siècle av. J.-C.
The site of Weyersheim «Les Hauts de la Zorn » (Bas-Rhin), excavated in 2014 by the Inrap, delivered for the first time in Alsace the remains of a forging workshop on a site occupied at the end of Hallstatt period and the beginning of La Tène period.

In addition to the discovery of numerous silos, having delivered typical ceramic and metallic artifacts, two structures (silo 1003 and pit 1014) localized at the southwest are distinguished by the impressive amount of metallurgical wastes $(110 \mathrm{~kg}$ of smithing wastes including almost 280 smithing slags). The analysis of the metallurgical waste revealed a post-reduction work, from bloomsmithing to the shaping of objects. Lithic tools, as well as a large batch of granite anvils, were also found. This atypical discovery allows us to question the place of metallurgy in Alsace in the 5th century BC.

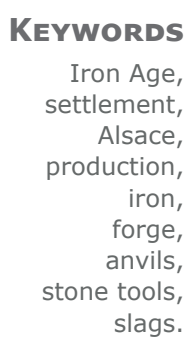


Le site de Weyersheim «Les Hauts de la Zorn » est localisé dans la plaine rhénane, à $15 \mathrm{~km}$ au nord de Strasbourg (fig. 1). Il occupe une zone assez plane (142,4 m NGF en moyenne) située à I'ouest du ban communal, rue de la Gare. Un léger pendage orienté N/S est visible, en direction du lit de la rivière Zorn. Sa découverte est consécutive aux recherches archéologiques liées à la réalisation d'un futur lotissement (6,2 ha diagnostiqués) [1]. La zone prescrite par le Service régional de I'Archéologie, d'une surface de 9900 m2, concerne le quart nord-ouest du projet (fig. 2) [2].

Bien que la majeure partie des vestiges mis au jour soient datables entre le Hallstatt D3 et La Tène ancienne, notons la découverte d'un dépôt de crémation du Bronze final I-IIb (str. 1060 [3]) à l'est, six structures oblongues non datées s'apparentant aux fosses à profils en $\mathrm{V}$ ou $\mathrm{Y}$ connues au Néolithique et à la Protohistoire [4] et deux structures modernes et contemporaines (une petite structure de chauffe et un silo à betterave).

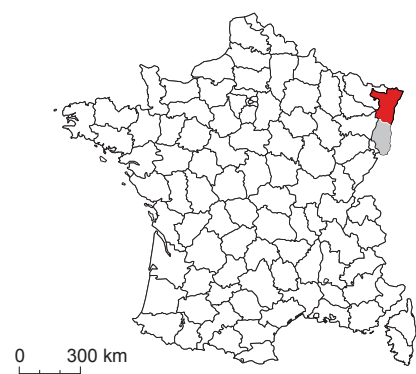

Figure 1 : localisation du site de Weyersheim dans le Bas-Rhin et des autres sites contemporains ayant livré des traces d'artisanat du fer (points rouges sur la carte). DAO : M. Michler.

1 - Rosheim
2 - Bischoffsheim
3 - Wolfisheim
4 - Holtzheim
5- Entzheim
6 - Souffelweyersheim
7 - Duntzenheim
8 - Gougenheim
9 - Mittelhausen
10 - Mittelshaeffolsheim

Les excavations de l'âge du Fer se répartissent quasiment sur l'ensemble de l'emprise de fouille (excepté à l'extrême est) et le site semble se développer au-delà de la limite ouest où se trouvent les structures liées au travail du fer. Un petit bâtiment sur poteau a été repéré au nord et la distribution spatiale des silos montre des effets d'alignement et de contrainte (deux bandes au nord et au sud). À proximité de ces structures de stockage se distingue la fosse 1014, où se pratiquait une activité de forge (accumulation de battitures et de restes de foyers en place). C'est la structure la plus originale du site, avec le silo 1003 qui a servi de fosse de rejet pour des déchets scorifiés. Lors du diagnostic, des déchets avaient également été

\section{[1] DABECK 2013.}

[2] MICHLER 2016.

[3] Datation sur os : 2925+/- 30BP, soit 1257-1019 BC à deux sigmas (Poz-71716).

[4] ACHARD-COROMPT \& RIQUiER 2013.

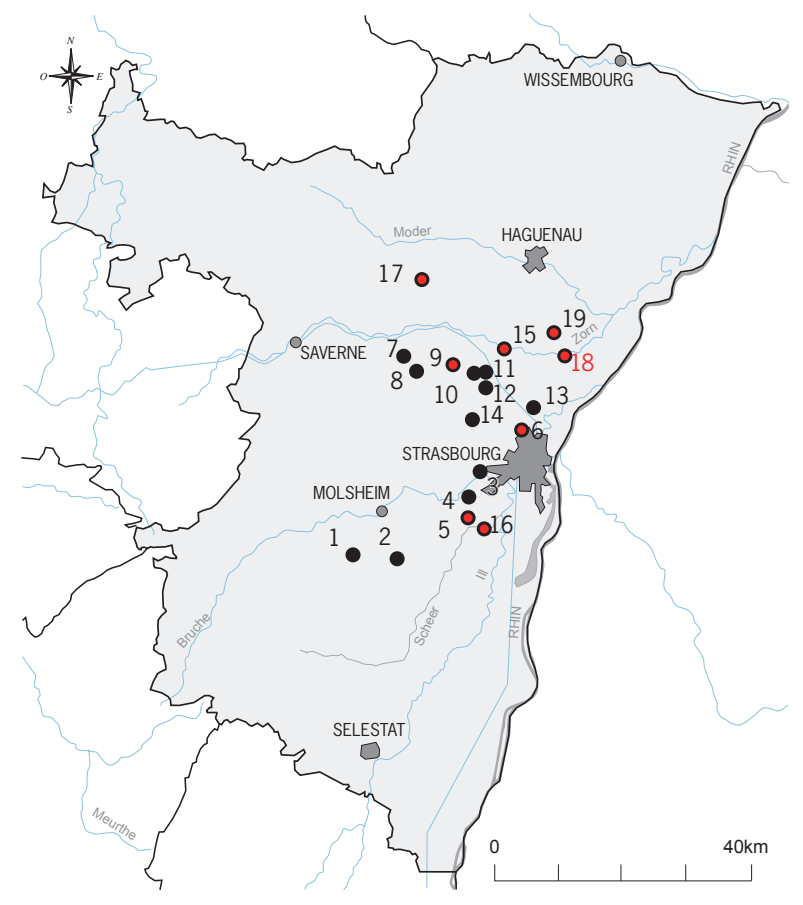




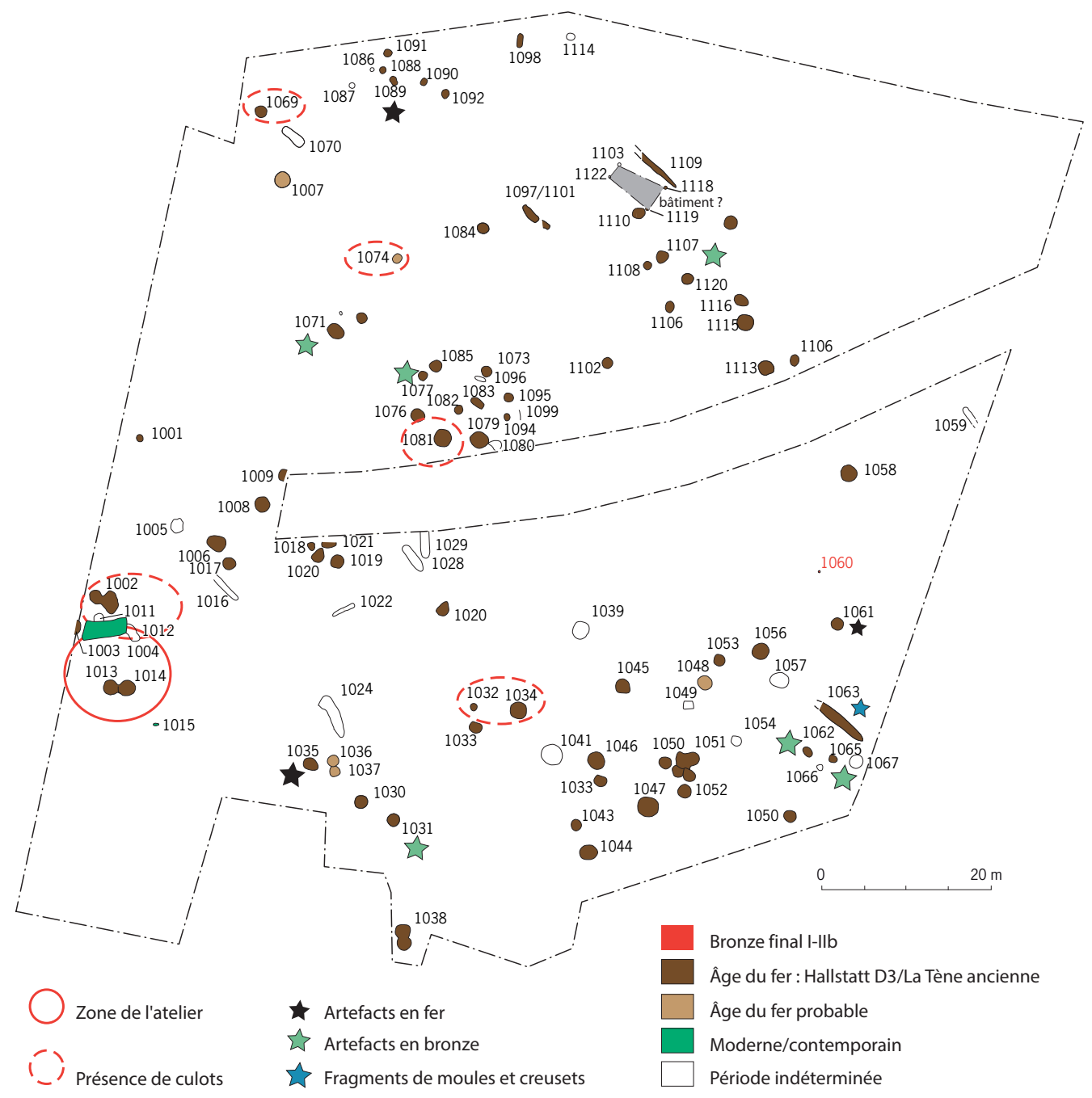

Figure 2

Plan phasé du site avec les structures ayant livré des objets en fer ou en alliage cuivreux, ainsi que des restes liés à l'artisanat du métal.

DAO : M. Michler, J.-L. Wuttmann, P. Girard.

découverts dans certaines structures (str. 19, 32, 40 et 45), mais les traces d'un artisanat du métal étaient illustrées par une seule fosse de combustion de taille réduite et mal datée (str. 07, plus à l'est, secteur non prescrit). De tels vestiges d'activité métallurgique encore inconnus régionalement ont par conséquent fait l'objet d'analyses poussées permettant d'illustrer une vocation particulière du site, même s'ils s'intègrent dans un contexte d'ensilage bien identifié, comme c'est le cas pour d'autres sites alsaciens contemporains.

Alors qu'en contexte rural les sites contemporains de Weyersheim ne livrent généralement que des indices d'une activité métallurgique ponctuelle, celui de« Les Hauts de la Zorn » se caractérise par une grande quantité de déchets liés à un travail de forge. Une place plus importante sera donc réservée à la présentation des activités métallurgiques. L'analyse que nous proposons complète d'une

[5] GentNer 2016. certaine façon l'article sur l'économie du fer dans le nord de la Forêt-Noire présentée dans cette même revue [5] en 2016.

\section{L'OCCUPATION DU HALLSTATT D3 À LA TĖNE ANCIENNE}

Soixante-douze faits appartiennent à cette phase et recouvrent l'ensemble de la zone prescrite (fig. 2). Des concentrations au nord, au sud et à l'ouest dans la zone de l'atelier suggèrent que le site s'étend par delà l'emprise de la fouille. Une spécificité du lieu est de concentrer à la fois des activités artisanales de forge et des silos.

Outre les structures de stockage (50 exemplaires), des fosses à contours ovales ou irréguliers (une dizaine), des cuvettes (5 exemplaires) et des restes de fossé (3 exemplaires) ont été mis au jour. Les artefacts découverts soulignent I'homogénéité chronologique du site. Le corpus céramique est comparable en volume à d'autres sites d'ensilage 


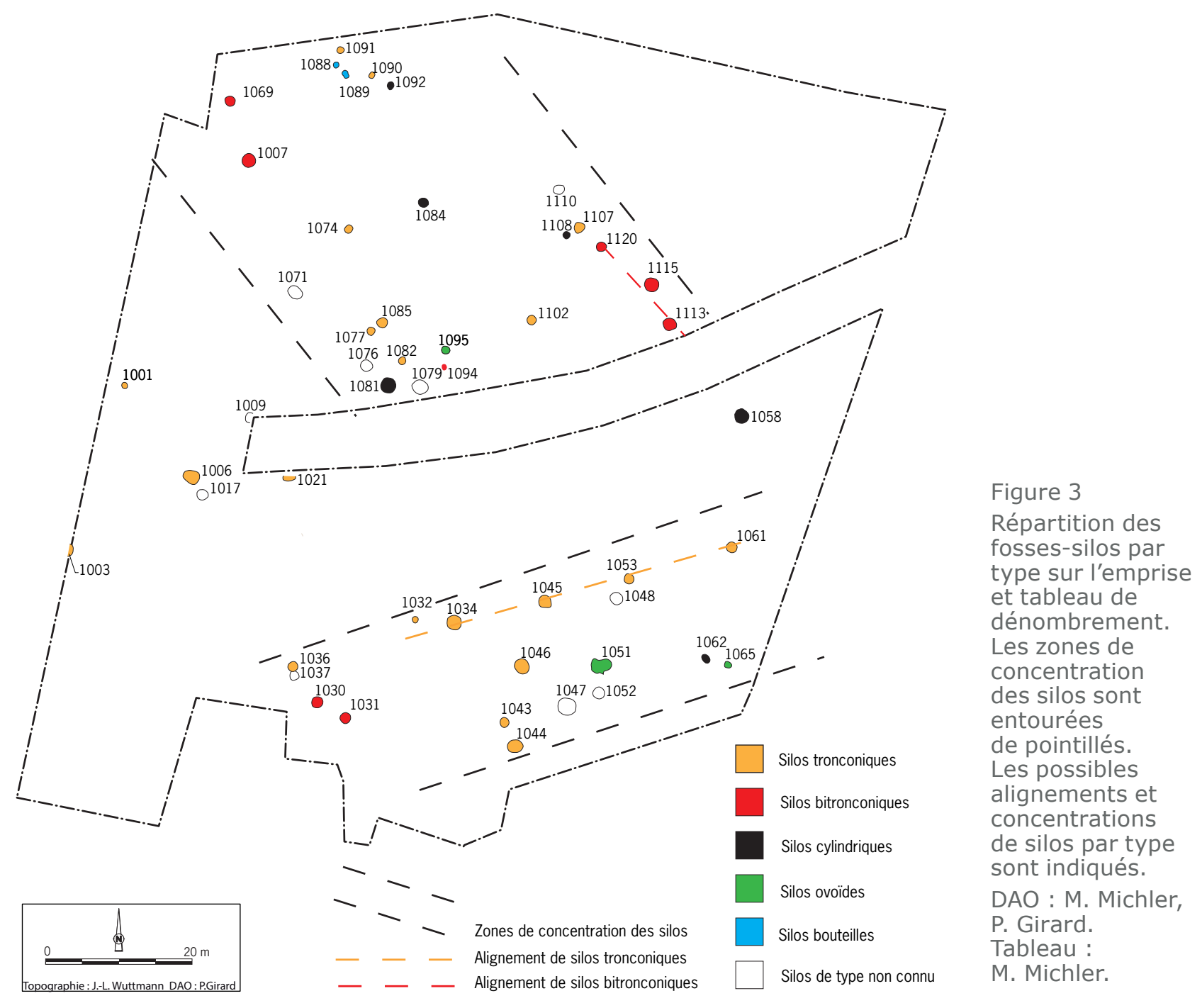

(Mittelhausen, « Liesbuehl/Gimbretter Weg 》 [6] par exemple) et les objets en bronze et en fer sont des parures, de l'outillage ou de l'armement.

\section{ORGANISATION SPATIALE ET NATURE DU SITE}

Les cinquante silos (fig. 3 et $\mathbf{4}$ ), majoritairement de section circulaire ou ovale se répartissent en cinq groupes morphologiques d'après leur profil : tronconiques (fig. 4, 1061), bitronconiques, cylindriques (fig. 4, 1058), ovoïdes (fig. 4, 1065) et en bouteille (fig. 4, 1088). Vingt-cinq ont $0,50 \mathrm{~m}$ ou plus de profondeur et d'après le calcul du taux d'érosion (formule de F. Gransar [7]) seule une vingtaine peut être considérée comme bien conservée. Comme le souligne M. Roth-Zehner, les sites d'ensilage restent

[6] CROUTSCH et alii 2015.

[7] GRANSAR 2002.

[8] MALRAIn et alii. 2013, p. 38.

\begin{tabular}{|c|c|c|c|}
\hline PROFIL & $\mathrm{Nb}$ & $\%$ & Numéros \\
\hline Tronconique & 21 & 42 & $\begin{array}{l}\text { 1001, 1003, 1006, 1021, 1032, 1034, 1036, 1043, } \\
\text { 1044, 1045, 1046, 1053, 1061, 1074, 1077, 1082, } \\
1085,1090,1091,1102,1107\end{array}$ \\
\hline Bitronconique & 8 & 16 & $1007,1030,1031,1069,1094 \mathrm{~B}, 1113,1115,1120$ \\
\hline Cylindrique & 6 & 12 & $1058,1062,1081,1084,1092,1108$ \\
\hline Ovoïde & 3 & 6 & $1051 \mathrm{~A}, 1065,1095$ \\
\hline Bouteille & 2 & 4 & 1088,1089 \\
\hline Non connu & 10 & 20 & $1009,1017,1037,1047,1052,1071,1076,1079,1110$ \\
\hline Total & 50 & 100 & \\
\hline
\end{tabular}

majoritaires en Alsace au premier âge du Fer, et ce jusqu'à La Tène B1 [8]. La prédominance des profils tronconiques est pour le moment une constance sur des sites contemporains.

Deux zones d'ensilage (partie nord et sud de l'emprise) sont visibles avec des largeurs de respectivement 46 et $23 \mathrm{~m}$. La zone de vide relatif entre les deux n'a pas pu être entièrement explorée ce qui limite la réflexion, mais soulignons que l'absence de vestiges pourrait-être liée à une zone de passage ou à la volonté de regrouper les silos pour des raisons pratiques ou topographiques (silos appartenant à différents groupes 


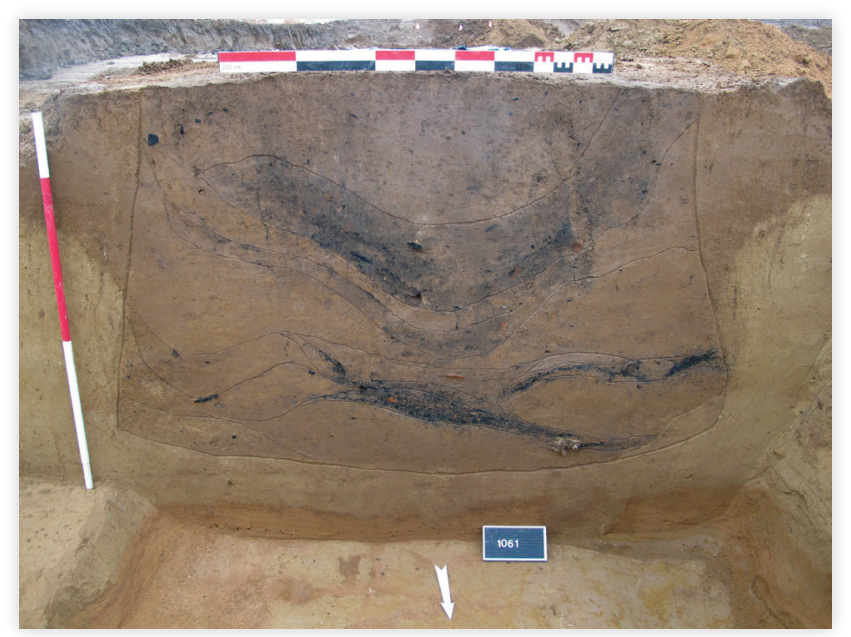

Structure 1061

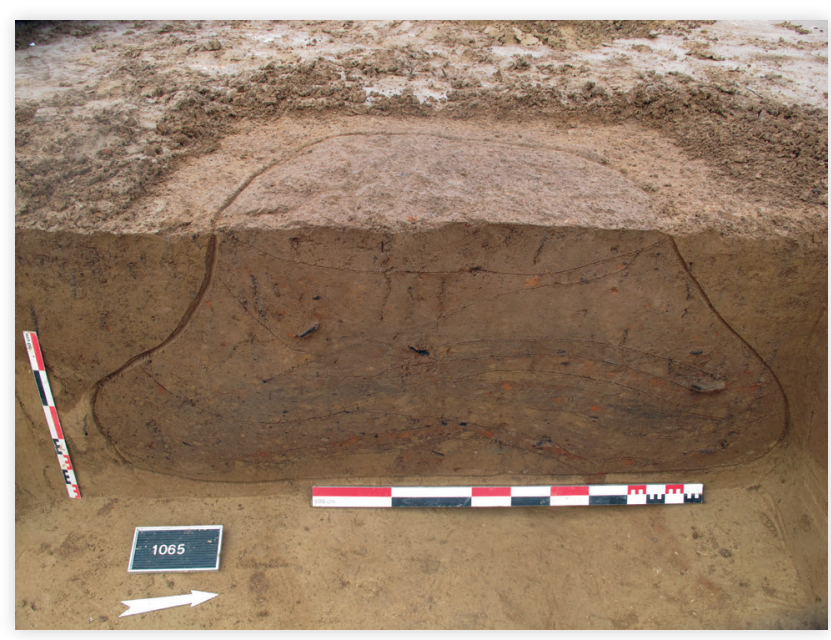

Structure 1065

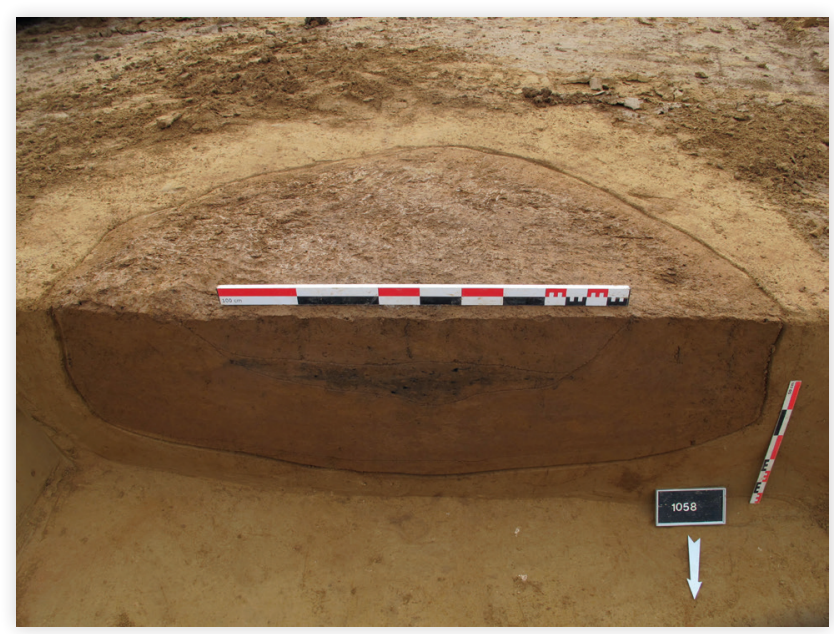

Structure 1058

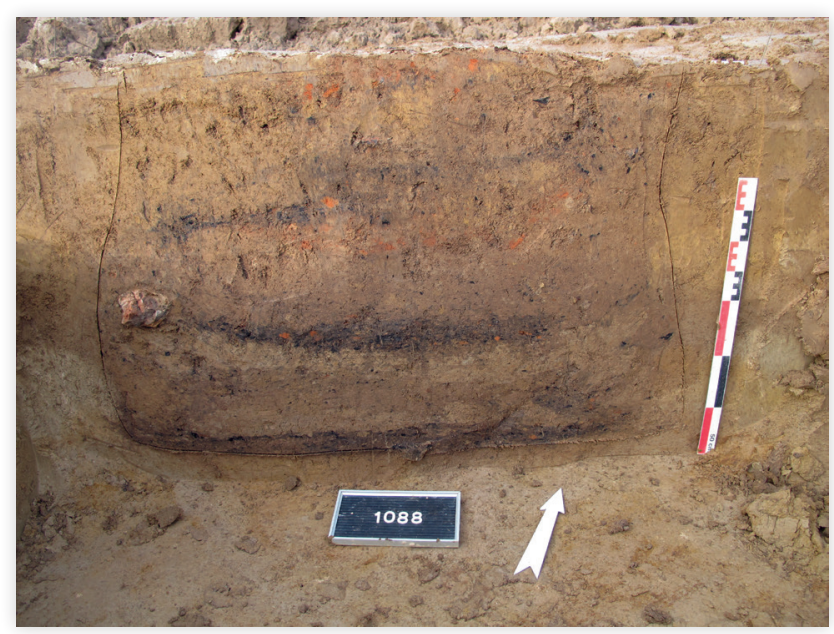

Structure 1088

Figure 4

Fosses-silos représentatives par type. Fosse tronconique (St. 1061), fosse cylindrique (St. 1058), fosse ovoïde (St. 1088), fosse en bouteille (St. 1088).

(C) Dessins et photos, équipe Inrap. DAO : P. Girard, mise en forme M. Michler.

familiaux par exemple, contrôle plus aisé sur des surfaces bien délimitées, réelles contraintes du terrain). Deux alignements de silos (fig. 3) dans la zone sud et au nord sont visibles. Ils pourraient s'agir de silos fonctionnant en batterie comme à Duntzenheim « Schlittweg », «Weingartenberg» [9] (Véber 2015). Le mobilier datant, qui ne permet pas une précision à la génération (environ 25 ans) limite les réflexions sur sujet.

Une tentative de calcul du volume utile des silos conservés à partir de leurs dimensions restituées n'a pas encore été faite. S. Defressigne et $M$. Landolt ont fait ce travail pour d'autres sites alsaciens et lorrains (du Hallstatt B à La Tène B) [10]. Ainsi, La capacité moyenne de stockage par site connaît une progression relativement constante avec le temps avec des capacités exponentielles jusqu'à
La Tène B. Si I'on compare le nombre de ces silos à celui d'autres sites contemporains, Weyersheim est bien doté (cinquante silos) [11], mais pour aller plus loin il faudrait lier ces nombres aux surfaces décapées. Par exemple, par rapport au site de Mittelhausen « Liesbuehl, Gimbretter Weg »[12] où $5000 \mathrm{~m}^{2}$ ont été décapés et trente-six silos mis au jour, la proportion de silo à Weyersheim est plus faible même si le nombre reste un des plus élevés pour la période.

Les limites de l'emprise rendent également difficile la compréhension de la topographie de l'atelier

[9] VÉBER 2015.

[10] Defressigne \& LANDOLT, 2017.

[11] Ibid., fig. 11.

[12] CROUTSCH et alii 2012. 
par rapport aux deux concentrations de silos mentionnés. Le silo 1003 d'où proviennent des culots est à la limite de décapage et pourrait être en lien avec des concentrations situées plus à l'ouest. Quoiqu'il en soit à Weyersheim l'activité métallurgique semble coexister avec les emplacements destinés au stockage (avec toute la prudence liée à la chronologie large), les silos étant très proches (moins de dix mètres). Ceci n'est pas le cas sur d'autres sites d'habitat à vocation agricole où ont été repérées des activités de réduction et de forge. Ainsi sur le site de Gondreville «Au Loup », c'est autour du regroupement de 131 silos que sont installés les grands bâtiments d'habitation et les nombreuses petites constructions de type « grenier surélevé »[13]. Les différentes activités sont bien séparées spatialement (à une centaine de mètres).

Les mêmes questionnements peuvent être posés quant à la position d'un petit bâtiment sur poteaux (peut-être de type «grange », comme à Illfurth «Buergelen » [14]) situé au nord de l'emprise, tout contre des silos et à plus de 70 mètres de l'atelier (figure 2 en grisé). Soulignons que les deux datations $\mathrm{C}^{14}$ sur charbon provenant de deux poteaux tombent dans le plateau du Hallstatt. S'agit-il d'un lieu de vie des populations responsables de ces structures de stockage, d'une zone artisanale de forgerons ou des deux ? Aucune réponse claire ne se dégage pour le moment. En Alsace, les sites datés du Hallstatt D3 à LaTène ancienne regroupant une unité d'habitation, des greniers et des silos sont encore rares, contrairement à la Lorraine où cette association est assez bien connue comme sur le site de Fontenoy-sur-Moselle « Les Herbues de Gondreville »[15]. Cette situation alsacienne résulte également de problèmes taphonomiques pour les structures faiblement ancrées.

Une réflexion plus large sur le statut particulier du site au vu de la présence exceptionnelle d'un atelier de forge et de nombreux rejets métallurgiques sera envisagée ci-après.

\section{PRODUCTIONS ET ARTEFACTS}

\section{La céramique}

Parmi le mobilier archéologique mis au jour, la céramique provient d'une quarantaine de structures et oriente la datation au HaD3/LTA. 2762 tessons ont été identifiés, correspondant à 275 vases pour un poids total de $6 \mathrm{~kg}$. Il s'agit de 145 formes basses pour 60 vases de forme haute. Les céramiques fines et mi-fines constituent le plus gros du corpus avec 173 individus pour 91 vases en céramique grossière. Les silos 1077 (fig. 5) et 1089 ont livré les plus gros ensembles. Les formes basses ouvertes à profil sinueux sont nombreuses. Quelques tessons présentent des dépôts blancs internes. On retrouve aussi des poignées de couvercle ou bien de couvre-feu.

Le «profil type» de la céramique de Weyersheim avec des décors incisés, des petites bouteilles et des formes sinueuses se retrouve au sein de la structure 1229, attribuée au Hallstatt D3, à EntzheimGeispolsheim «Aéroparc (LIDL-CUS)» [16]. Mais des comparaisons avec la céramique des structures 1608 et 1609 d'Entzheim plus tardives (Ha D3-LT A) sont possibles.

Il est important de souligner que la céramique tournée manque dans le corpus. Sa présence peut parfois illustrer un site de rang supérieur, ce qui aurait été envisageable avec la présence de l'atelier de forge. De plus aucun véritable stigmate en lien avec l'activité métallurgique n'a été observé sur les tessons. Toutefois la présence de céramique en situation de rejet, suggère fortement que I'habitat des populations agricoles et des artisans est à proximité.

Des objets assez fréquents pour cette période comme un anneau, une cuillère et six fusaïoles en terre cuite ont également été découverts.

\section{La faune}

177 des 298 restes osseux d'animaux terrestres $(5,2 \mathrm{~kg})$ mis au jour dans la fouille sont datés de la fin du Hallstatt au début de La Tène ancienne (fig. 6). Ils proviennent de 19 des 82 structures excavées attribuées à cette période. Bien que le nombre de structures soit sensiblement égal entre les moitiés nord et sud de l'emprise (fig. 8), seuls deux échantillons (1102 et 1113) appartiennent à la moitié nord, les 17 autres relevant plutôt de la moitié sud. Ce matériel osseux, assez bien conservé, se compose d'un squelette de chien, de cinq ramures de cerfs élaphe et de 124 restes attribués à des déchets alimentaires [17].

Le squelette d'un jeune chien adulte d'environ 24 mois, quasiment complet au moment de sa découverte, a été mis au jour dans le silo 1052 (fig. 8). La posture du cadavre, et sa localisation dans

[13] Defressigne \& LeROY 2013.

[14] Roth-ZEHNER, 2013, p. 59, fig. 4, type 3.

[15] Defressigne \& LANDOLT, 2017, p. 85, fig. 6.

[16] LANDOLT et alii 2007.

[17] PUTELAT 2016. 
Figure 5 : vases issus de la structure 1077.

(C) M. Van Es, P. Girard, Inrap.

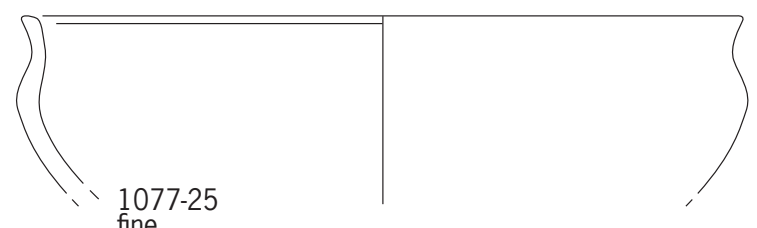

1.
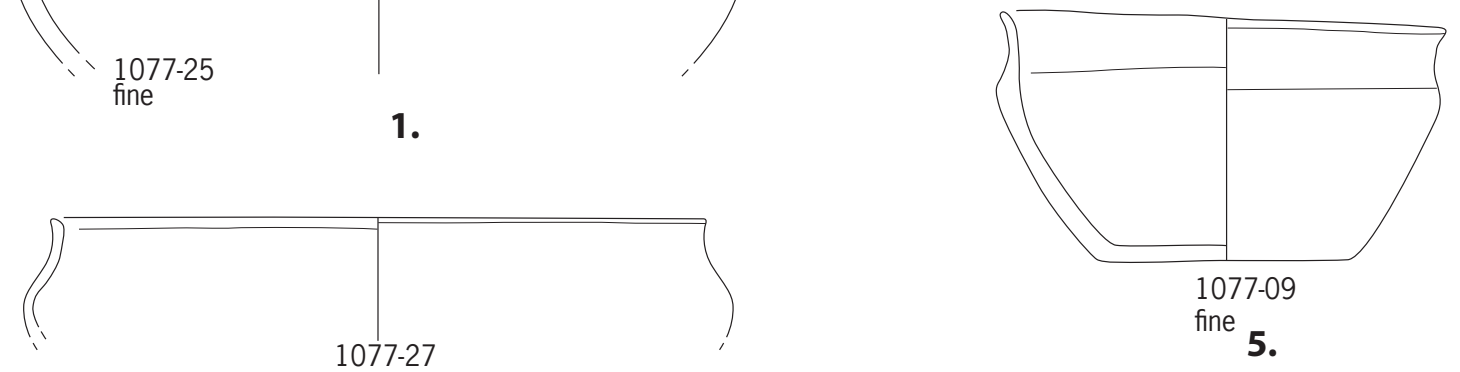

2.

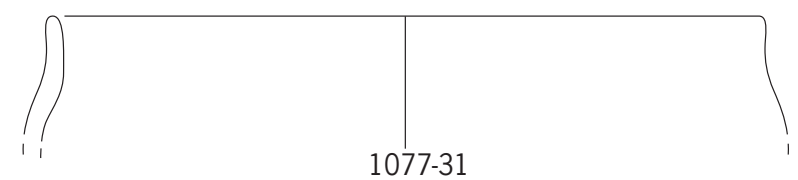

3.

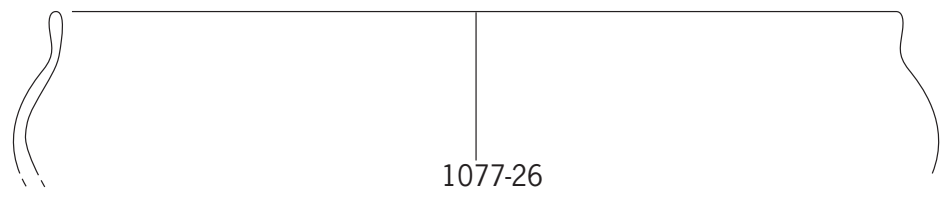

4.

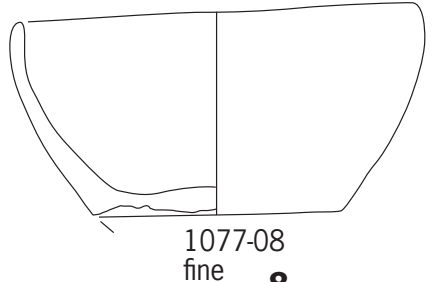

8.

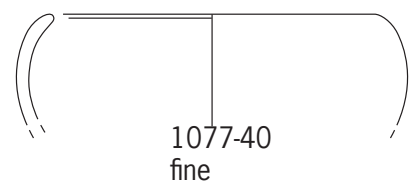

11.

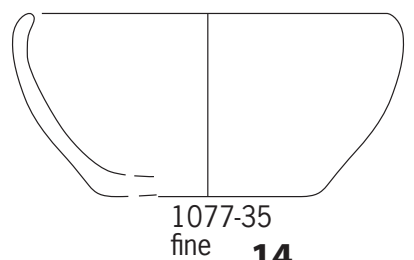

fine 14.

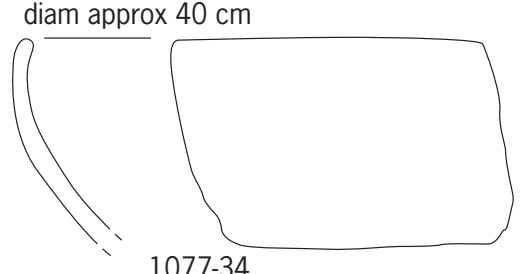

9.

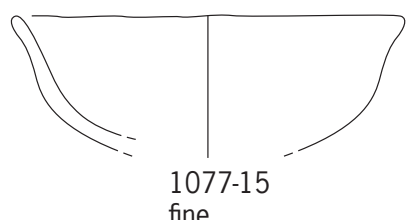

6.

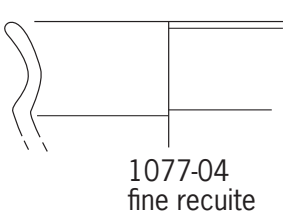

7.

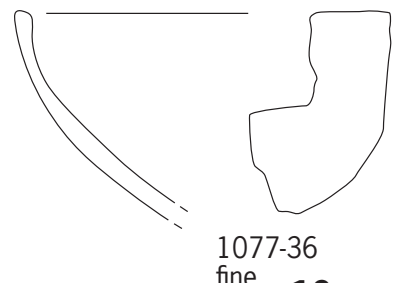

10.

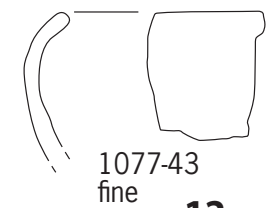

12.

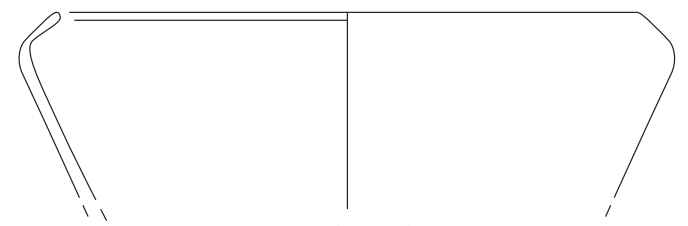

1077-13

13.

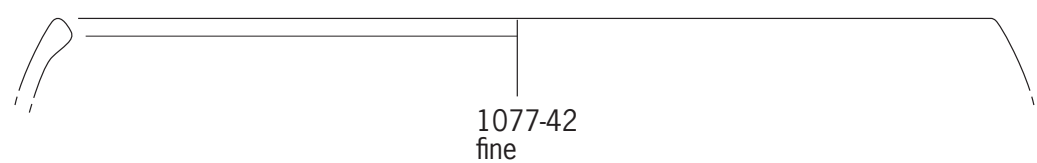

15.

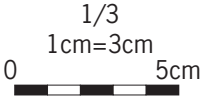


Figure 6

A. Répartition spatiale des ramures de cerfs élaphe et des déchets osseux d'origine culinaire (carrés rouges).

B. Vue d'ensemble des deux ramures du silo 1030.

C. Squelette de chien 1052 in situ.

(c) Photos équipe Inrap, Dao : P. Girard, mise en forme O. Putelat.
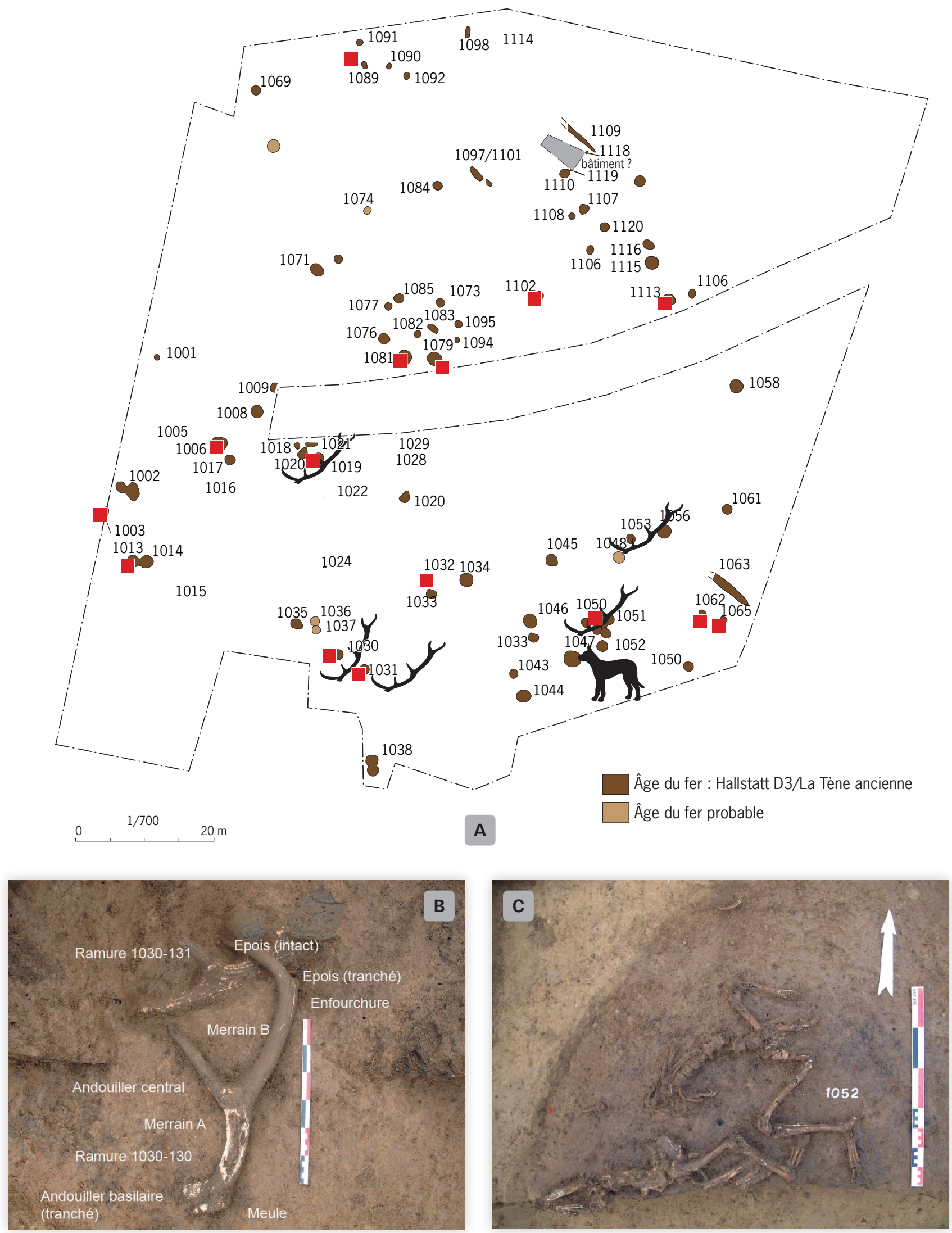

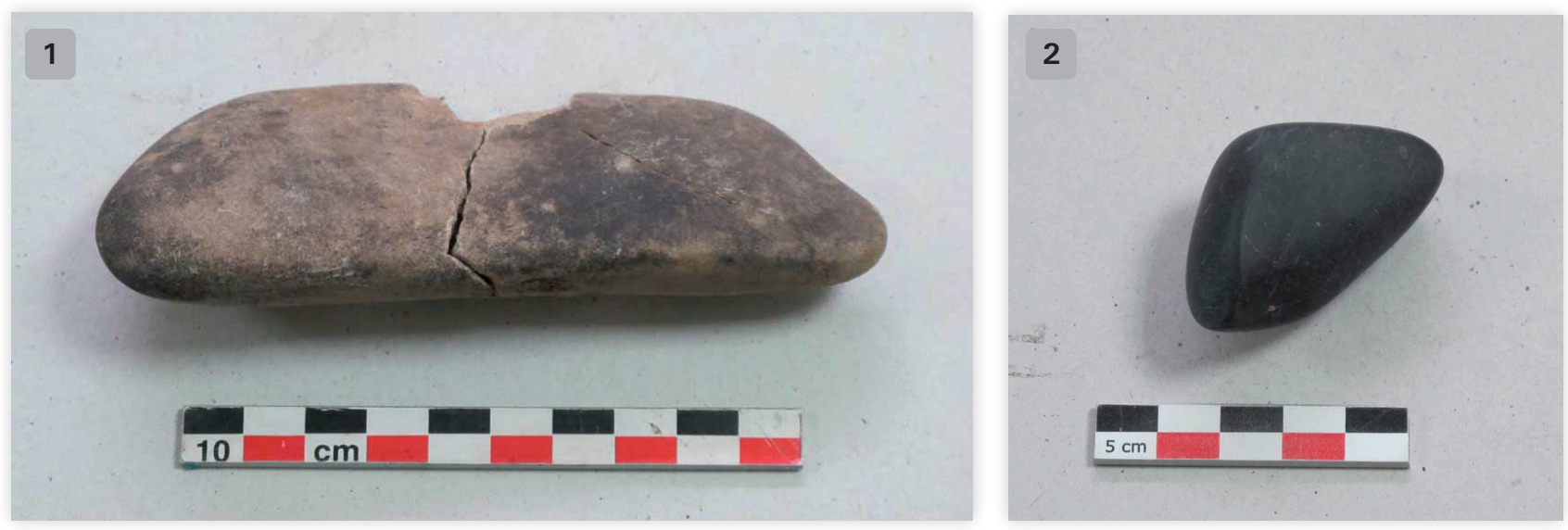

Figure 7 : outillage lithique :

1. Lissoir aiguisoir $1063-03$; 2. Brunissoir ou pierre de touche 1085-2.

(C) F. Jodry, Inrap.

une couche de déblais, évoquent un rejet opportuniste. Toutefois, le rapprochement de cette découverte avec de nombreux autres dépôts de cadavres d'animaux, recensés en Alsace pour La Tène ancienne, invite à ne pas négliger I'hypothèse d'un dépôt intentionnel, différencié de la seule problématique du rejet [18]. Il serait de fait envisageable que le cadavre du chien de Weyersheim s'insère dans l'ensemble des dépôts d'animaux dits « dépôts particuliers » témoignant de « pratiques rituelles domestiques » [19].

Il pourrait en être de même des cinq ramures de cerfs élaphes (dont au moins trois sont des bois de mues), découvertes lors de la fouille des fosses et silos 1020, 1030, 1050, 1053. Leur répartition montre une localisation dans la moitié sud de la fouille (fig. 6). Des prélèvements de matière dure sont avérés dans trois cas sur cinq [20]. Ils restent cependant limités à une partie des pointes, sans concerner les merrains. Il faut de plus noter qu'aucun déchet de débitage de bois de cerf n'a été découvert, ce qui attesterait une activité tant soit peu conséquente et précise du travail des matières dures animales. Ces découvertes de bois peuvent être rapprochées de deux autres trouvailles bas-rhinoises, faites à Entzheim-Geispolsheim «Aéroparc » (fosse 1088, transition Hallstatt D3 La Tène) [21] et Holtzheim «Am Schuesselberg » (fosse 51, Hallstatt D3) [22] pour lesquelles I'hypothèse de dépôts symboliques avait déjà été évoquée.

Les 124 restes osseux attribués à des déchets alimentaires $(1,8 \mathrm{~kg})$ proviennent de 15 faits des 82 faits datés de la séquence de l'âge du Fer et 96 $\%$ d'entre eux ont été mis au jour dans la moitié sud de l'emprise. Les effectifs de chaque taxon sont inférieurs au seuil de représentativité de 50 restes [23], ce qui nous invite à considérer avec prudence ces données qui traduisent surtout des tendances. Le porc (NR : 25 ; NMI : 3) compose le tiers des 76 restes déterminés et prévaut en fréquence d'occurrence, étant présent dans 12 des 15 échantillons. La masse de ces restes ne représente que $14 \%$ du total, mais les parties les plus riches de la carcasse (jambonneaux, jambons) étant les mieux représentées, il est évident que la contribution du porc à la part carnée de l'alimentation est très conséquente, d'autant que la consommation d'animaux lourds semble privilégiée : un juvénile-subadulte d'environ 24 mois et un adulte de réforme, âgé de 5-7 ans contre un infantile-juvénile de 3-12 mois.

Le bœuf (NR : 22 ; NMI : 2) prévaut selon la masse des restes (61 \% du total). Il est présent dans 11 des 15 échantillons, ce qui atteste une bonne répartition spatiale. L'ensemble de ces paramètres converge pour montrer la prévalence de la viande bovine dans la ration carnée.

Les caprinés (NR : 13 ; NMI : 2), où les ovins et les caprins ne sont pas différenciés, occupent la troisième place, en nombre de restes, en nombre d'individus et en fréquence d'occurrence. Cette dernière est de moitié inférieure à celle du bœuf et du porc (6 échantillons sur 15), ce qui tendrait à indiquer une répartition spatiale moins prononcée et donc sans doute une consommation moins courante.

[18] Putelat \& LANDOLT, 2013.

[19] AuXIETTE et alii 2010.

[20] Putelat, 2016.

[21] PUTELAT 2007.

[22] KuHnLe \& TeSnier-Hermetey 2005.

[23] PUTELAT 2015. 
Une pratique cynophagique occasionnelle est attestée par la présence de 11 restes (fosse 1061), marqués de traces de découpe, et attribués à un même jeune chien adulte d'environ 24 mois. Aux équidés ne sont attribués que deux restes. Trois restes (un fragment de tête osseuse de cerf élaphe, une côte et un tibia de sanglier) illustrent la chasse de grand gibier, et, bien que la proportion totale des restes de gibier soit relativement basse (environ 4 $\%$ du NRD), la part non négligeable tenue par la masse des restes de ce grand gibier dans l'échantillon ( $7 \%$, soit autant que les caprinés), laisse entrevoir une certaine importance de l'apport de la chasse à la ration carnée.

Sous l'angle de l'activité métallurgique, il est intéressant de rappeler que la plupart des ossements d'animaux sont issus de la moitié sud de l'emprise, où se situent les silos 1003 et 1014, caractérisés par l'abondance des rejets liés au travail du fer. Il paraît donc probable que ces rejets osseux soient au moins en partie imputables aux forgerons ou à leurs proches. Toutefois, le silo 1003 ne livre que sept restes d'animaux, tandis que le silo 1014 n'en livre apparemment pas. Seuls quatre des 124 restes sont marqués de traces d'ustion non culinaire, ce qui permet d'écarter toute hypothèse d'utilisation délibérée de l'os en tant que combustible durant le travail du métal, à la différence de ce qui avait été observé à La Tène ancienne au nord du Massif jurassien, sur le site de Chevenez « Combe En Vaillard » [24].

La comparaison des données archéozoologiques de Weyersheim avec d'autres, livrées par 14 sites alsaciens (ou géographiquement proches), tous datés entre le Hallstatt final et La Tène ancienne, a été effectuée avec prudence, en raison de la ténuité du corpus faunique de ce site [25]. Parmi les huit principaux taxons (NR8), l'échantillon de Weyersheim se distingue par une proportion de restes de caprinés très inférieure à la moyenne régionale ( $17,1 \%$ versus $36,2 \%$ ) et par une proportion de restes de porcs nettement supérieure à la moyenne régionale (32,9\% versus $21,9 \%)$. La proportion des ossements de grands gibiers, un peu plus élevée que la moyenne régionale (3,9\% versus 1,9\%), doit aussi être soulignée.

La situation géographique de Weyersheim, entre Kochersberg et Ried, ainsi que les caractéristiques environnementales qui en résultent, ont sans doute entraîné ici une plus forte représentation du bœuf et du porc, mieux armés que les caprinés pour s'adapter aux sols humides. La bonne représentation du porc (souvent engraissé en forêt aux périodes anciennes), la mise en évidence de la chasse de grand gibier, et celle de la collecte de bois de mues, ainsi que les relations « homme-forêt » que tout cela implique, doivent sans doute être évaluées en tenant compte du rôle tenu par la métallurgie dans l'existence des occupants du site. Enfin, s'il nous paraît probable qu'une pratique cynégétique plus intense qu'ailleurs est induite par la proximité du Ried et par un certain opportunisme, il n'en reste pas moins que la chasse au sanglier nécessite courage, armement, voire une certaine organisation sociale.

\section{Outillage macro-lithique (hors artisanat lié au métal)}

Sept petits galets de quartzite, de gneiss et de grès fin ont été inventoriés dans le lot des outils lithiques (St. 1006, 1053, 1063, fig. 7). Leurs surfaces actives sont planes ou convexes, d'aspect poli et marquées par quelques impacts et traces noires de frottement. Il s'agit principalement de lissoirs pour la céramique (panse et décors, Leuvrey 1999). La sphère alimentaire est représentée par une seule molette en grès grossier (1063-1) à surface active lisse et polie.

\section{Les objets en alliage cuivreux et en fer (fig. 8)}

Deux bracelets fins en bronze proviennent de structures adjacentes (str. 1071, 1077), comme des éléments de fibules de type F3B1, proches du fossé 1063 d'où proviennent aussi des restes de creusets ou moules en terre cuite - on peut avancer I'hypothèse d'un petit atelier de bronzier dans cette zone, fig. 8, 6 et 7 - et du silo 1061. Un petit galet noir (1085-2, fig. 7, 2), dont la surface active lisse est marquée de microstries et de traces cuivrées pourrait être une pierre de touche, mais c'est à confirmer.

La présence concomitante d'un artisanat du bronze et du fer est connue sur différents sites de cette période et n'est pas limitée aux seuls habitats fortifiés de hauteur (comme «La Cité d'Afrique » à Messein en Lorraine ou le Britzgyberg à Illfurth en Alsace).

Les objets en fer quant à eux se trouvaient dans des fosses et silos éparpillés sur le site. L'herminette (silo 1089) était associée à un lot important de céramique (fig. 8, 2). On a également découvert un fer de lance à flamme large (fig. $8, \mathbf{3}$ ), ainsi qu'un petit ciseau (fig. 8, 1).

[24] Putelat 2010.

[25] Putelat 2016. 


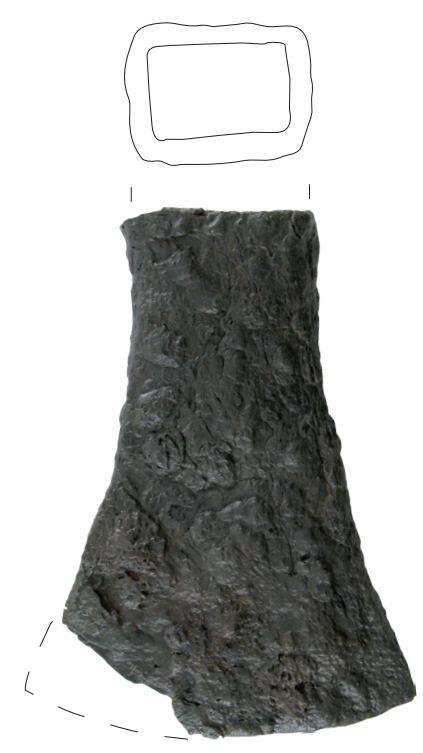

6259-MFE-1089-1

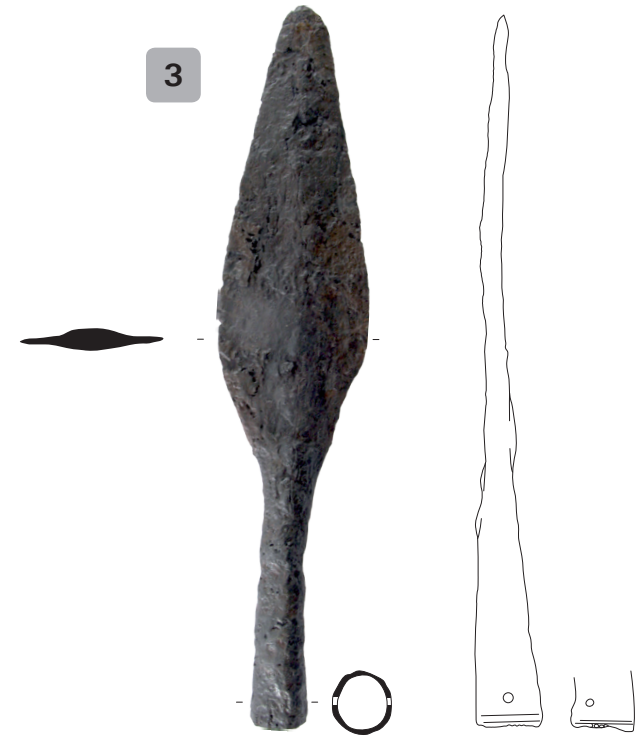

6259-MFE-1061-1

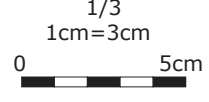

4

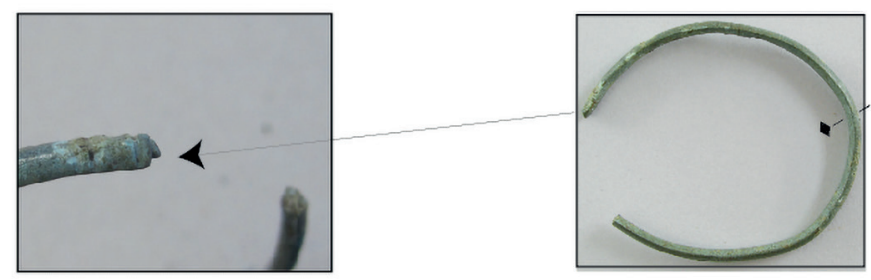

6259-MCU-1071-1
2

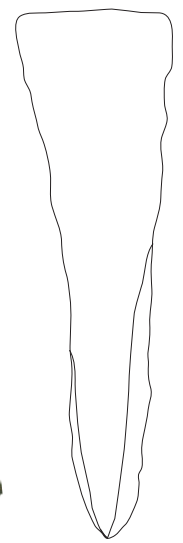

5

Figure 8

Objets en fer :

1. Ciseau, 2. Herminette, 3. Fer de lance.

Objets en alliage cuivreux :

4. Bracelet fin, 5. Fibule à pied décoré,

6 et 7. Creusets et moule en terre cuite.

(c) M. Michler, D. Minni, Inrap.

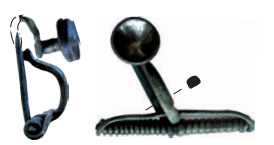

6259-MCU-1062-1 


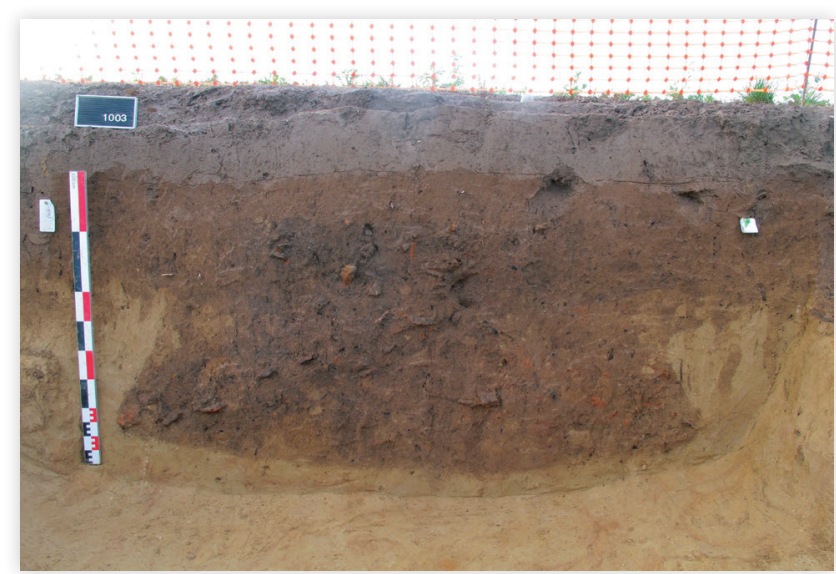

Figure 9 : vue vers l'ouest du silo St.1003, utilisé entre autres comme dépotoir de I'atelier de forge. Seule la moitié est a été fouillée, l'autre moitié est située hors emprise.

\section{(C) cliché P. Clerc, Inrap.}

Ces différents objets appartiennent à des types bien connus sur les sites contemporains régionaux et dans le domaine hallstattien centre-occidental [26] (Dubreucq 2013). Pour le moment il n'est pas possible de savoir s'ils proviennent de l'atelier de forge proche, mais leur présence montre que la chasse a pu être pratiquée sur le site (cf. partie sur la faune) tout comme l'artisanat du cuir.

Pour l'artisanat du fer, les déchets métallurgiques se trouvent dans des silos parfois à plus de $70 \mathrm{~m}$ de l'atelier, mais en grande majorité dans la partie ouest de l'emprise. Ces rejets semblent pour le moment aléatoires, comparés à celui massif de nombreux culots dans le silo 1003.

[26] DUBREUCQ 2013.

\section{L'ARTISANAT DU FER ET LES STRUCTURES ASSOCIÉES}

Le silo 1003 et la fosse 1014, distante de quelques mètres, concentrent les vestiges d'un atelier de forge abandonné il y a près de 2500 ans.

\section{LE SILO 1003 (FIG. 9)}

Circulaire (diam. 1,40 m) et tronconique, ce silo n'est conservé que sur $1 \mathrm{~m}$ d'épaisseur. En limite d'emprise, seule une moitié a été fouillée et a livré plus de $23 \mathrm{~kg}$ de scories et plusieurs boules de terre cuite. La céramique (formes basses et moyennes à profil sinueux, pots) date le comblement du Ha D3-LTA.

\section{LA FOSSE 1014 (FIG. 10 ET 11)}

Cette fosse semble fonctionner avec une structure voisine très arasée (St 1013) et a livré un matériel archéo-métallurgique exceptionnel, tant par la quantité que par la diversité des éléments.

Trois phases distinctes ont été mises en évidence : - une phase de fonctionnement s'achevant par la destruction des foyers et le rejet des déchets d'activité sidérurgique.

- une phase de comblement des matériaux issus du démantèlement du (ou des) foyer(s) et d'une bonne partie de l'outillage de l'atelier (enclumes).

- une phase d'abandon et de recouvrement de la fosse.

Les datations C14 réalisées sur des charbons de bois des niveaux de comblement et de fonctionnement proposent respectivement $2430 \pm 30 \mathrm{BP}$ et $2465 \pm 30$ BP (problème du plateau hallstattien entre le viıi et le ve siècle av. J.-C., soit 740-403 et 760-414 BC à deux sigmas).

Figure 10 : vue du début de la fouille de la fosse 1014.

À gauche : mise au jour des premiers grands fragments de terre cuite et des blocs de granite. À droite : dégagement des niveaux superficiels (US.4, US.12 et US.13).

(C) clichés P. Clerc, Inrap.
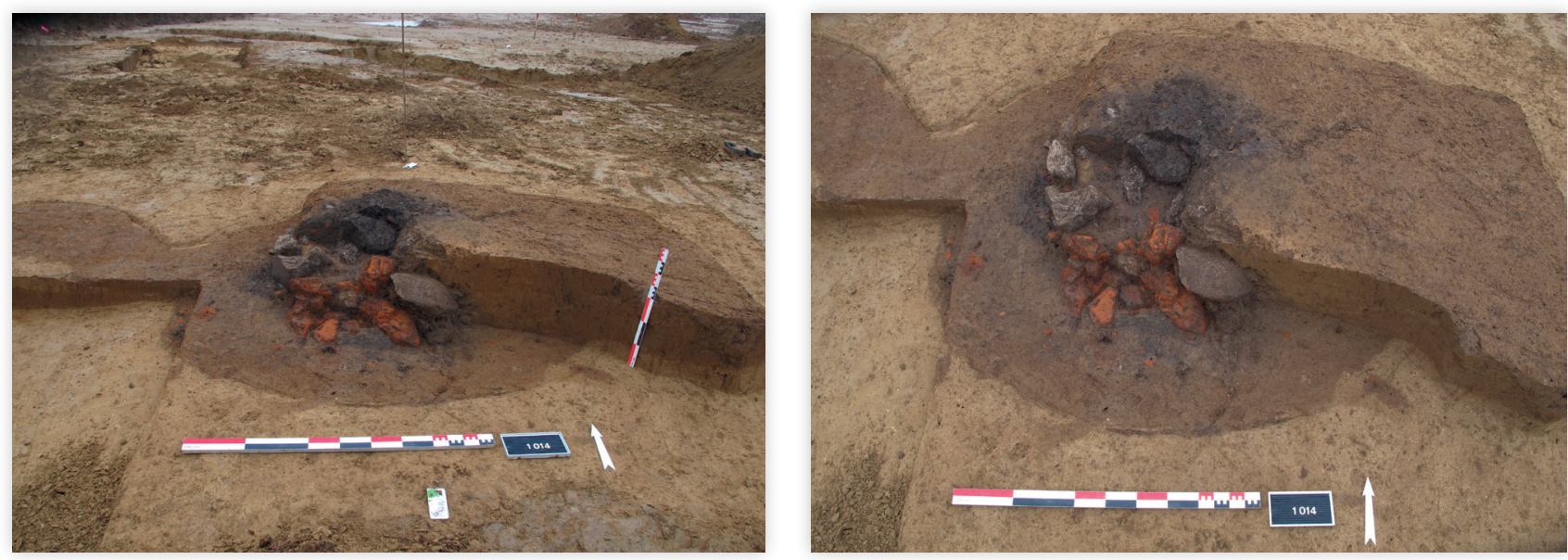
Figure 11

1. Relevé des faits 1013 et $1014 ;$ 2. Relevé du foyer de Sevaz

(Suisse), d'après Benkert et alii 2010, figure 23.

(c) P. Clerc, P. Girard, M. Michler.
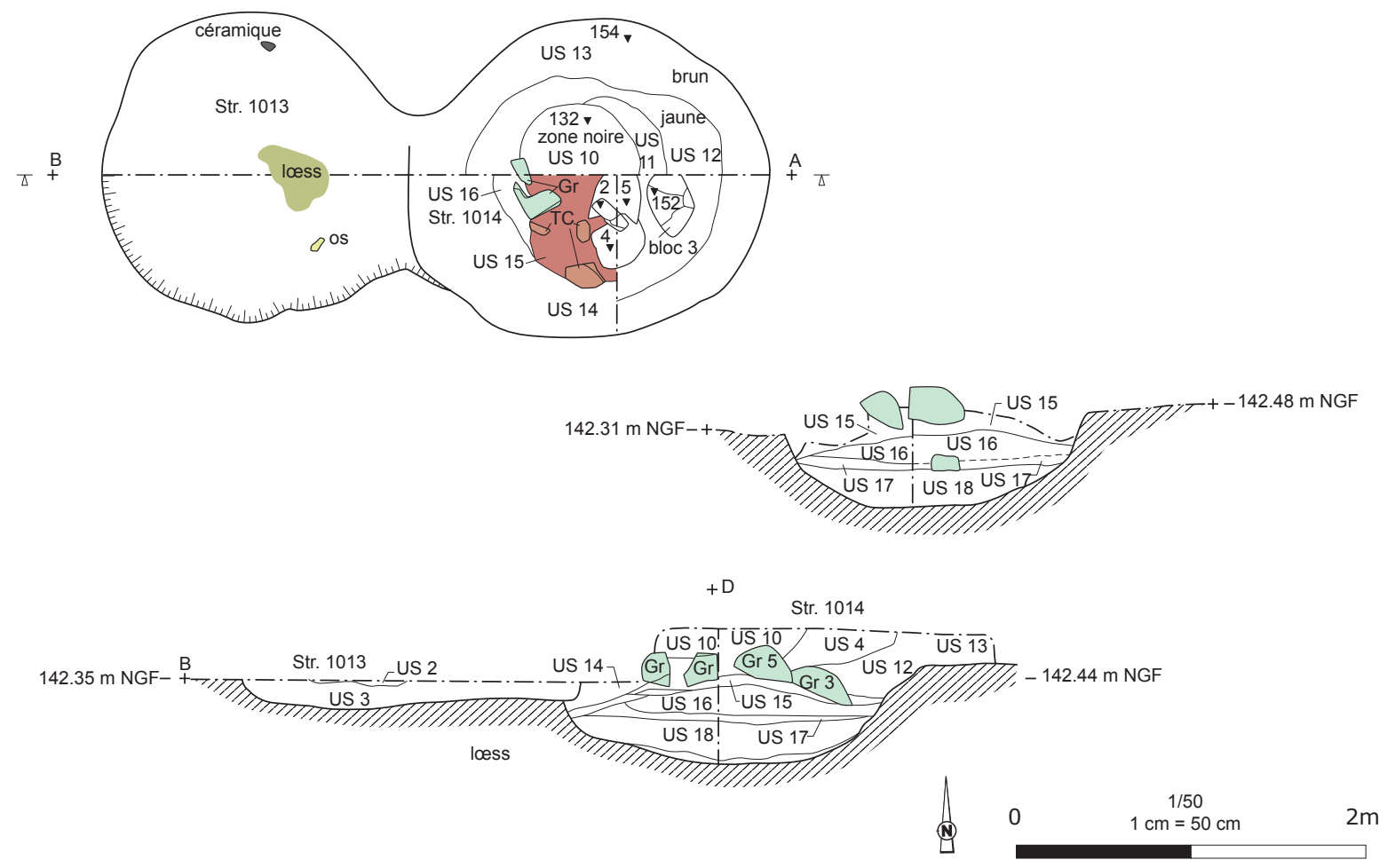

US 2 - limon loessique brun-jaune.

US 3 - limon argileux brun, compact et homogène, avec de très rares micro-charbons de bois, 1 tesson et 1 os.

US 10 - limon argileux brun-noir, compact et hétérogène avec de nombreux fragments de TC et un bloc de granit.

US 11 - limon argileux brun-jaune foncé, compact et homogène, avec présence de charbon de bois, et de taches de TC de très petites dimensions.

US 12 - limon argileux et lœssique jaune, compact et homogène, avec présence de rares charbons de bois.

US 13 - limon argileux brun.

US 14 - limon argileux brun-noir.

US 15 - accumulation de blocs de TC orangée avec localement des traces de vitrification, parfois de plaques de TC et peu de scories en partie centrale et d'avantage sur les bords.

US 16 - limon argileux avec de nombreuses scories sur les parois et des nodules de TC, et présence d'un fragment de céramique.

US 17 - limon argileux noir, compact et hétérogène, très riche en scorie et présence de 2 blocs de granit.

US 18 - lœss brun clair compact et homogène, absence de trace de charbon de bois, de scorie ou de céramique.

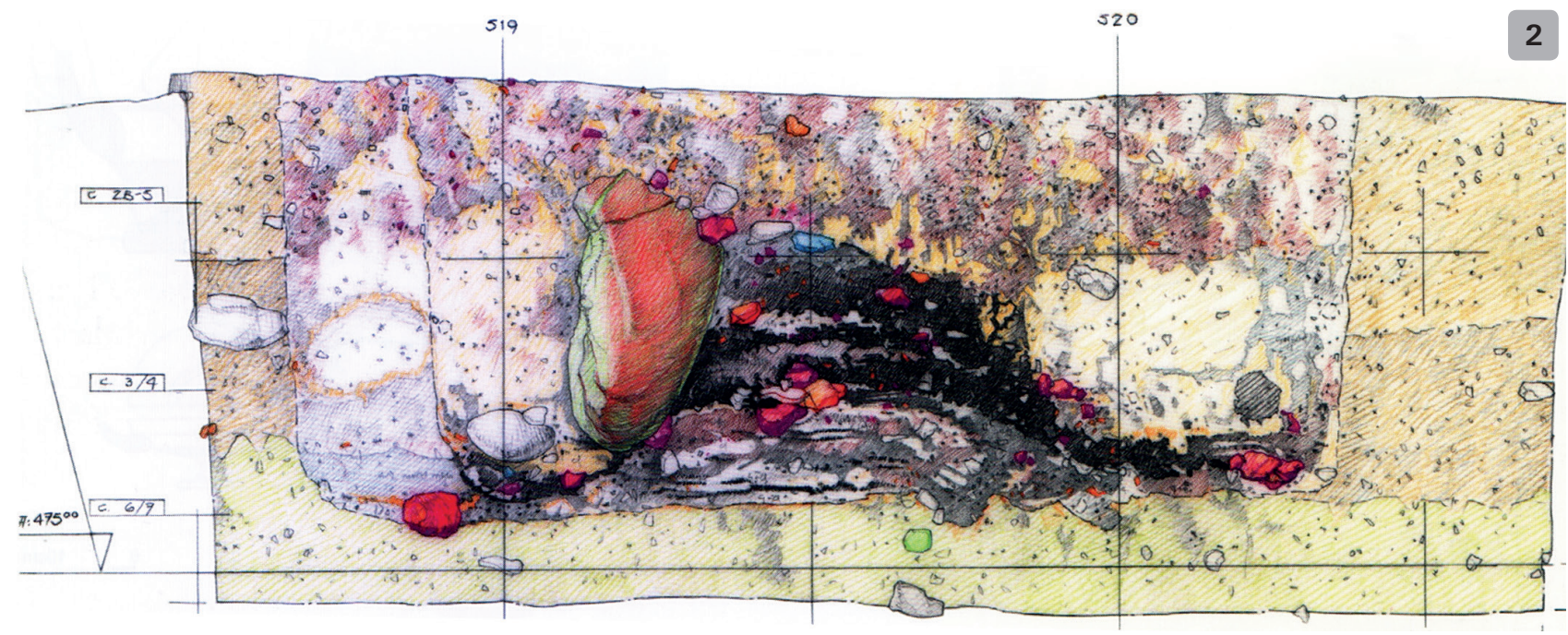




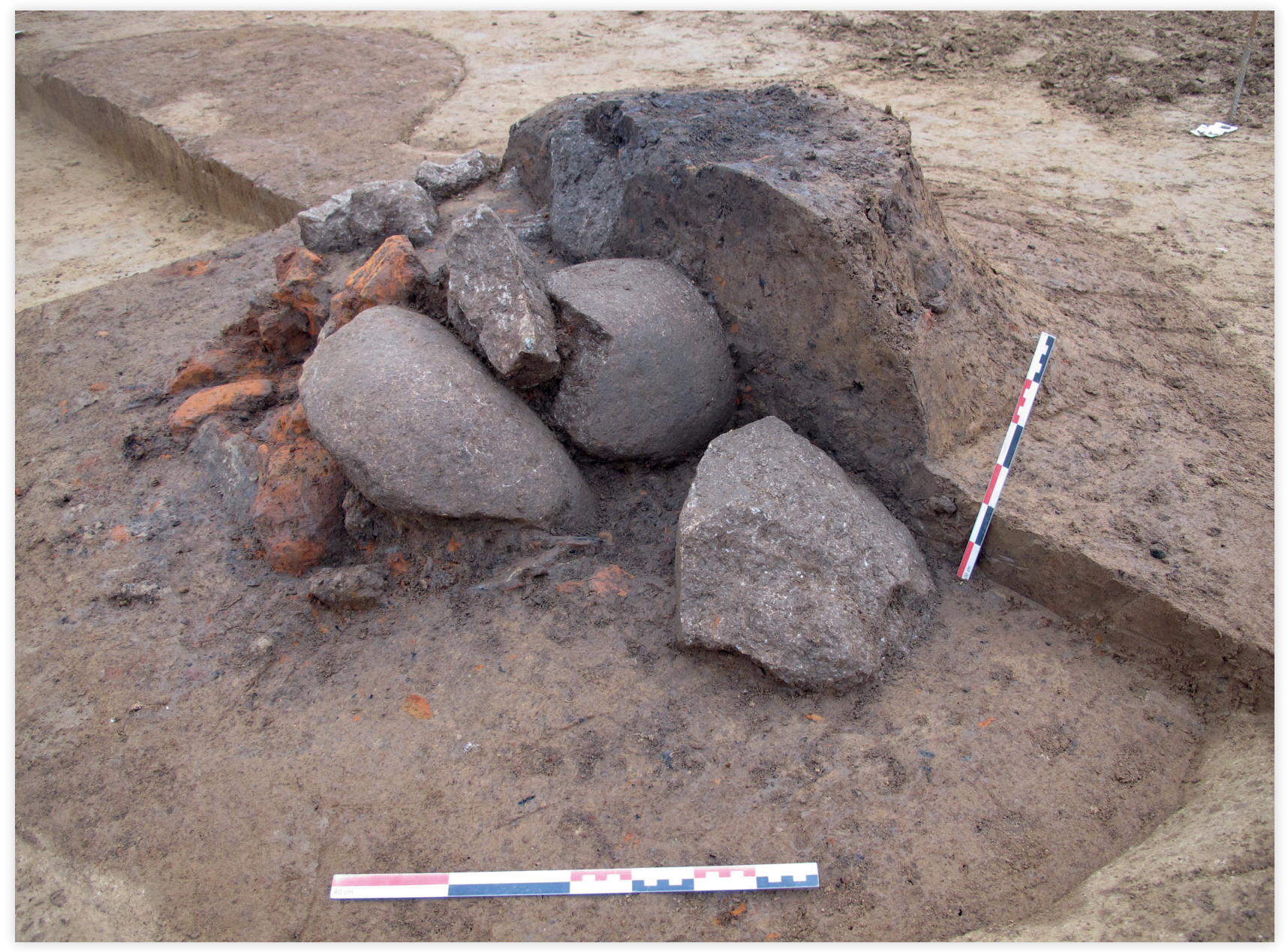

Figure 12

Vue des premiers blocs de granite découverts dans le comblement de la fosse 1014. (C) cliché P. Clerc, Inrap.

\section{L'ABANDON}

Les niveaux supérieurs de la fosse contiennent et recouvrent les blocs évoqués ci-après. Ils sont pauvres en artefacts et scellent les couches sous-jacentes.

\section{UN LOT EXCEPTIONNEL D'ENCLUMES ABANDONNÉES (FIG. 12)}

La fouille a livré une série de seize blocs granitiques en position secondaire au centre de la structure et reposant sur une couche riche en matériaux archéo-métallurgique.

Certains blocs dépassant les $40 \mathrm{~kg}$ sont intacts, alors que d'autres montrent des cassures relativement fraîches situées sur des zones actives. Ce lot est exceptionnel pour cette période en Europe et illustre les supports de frappe d'un atelier sidérurgique.

[27] BocQUILLON et alii 2009, p. 104, fig. 17.

\section{PLUSIEURS FOYERS DÉMANTELÉS SUR PLACE (FIG. 13)}

Plus de $26 \mathrm{~kg}$ de terre cuite ont été prélevés : parois de foyers de différentes tailles (fig. 13, 1), fragments de tuyères avec conduit de ventilation, bouchons (fig. 13, 2), etc. Des éléments de comparaison sont connus (site contemporain de Vrigny, « Cumines Basses », Marne [27]).

Les foyers dont le dénombrement reste à faire, sont illustrés par des éléments de parois vitrifiées sur près de $2 \mathrm{~cm}$ d'épaisseur. Le plus grand fragment à évent est de forme carrée (20 cm de côté).

Ce niveau correspond à une seule et même phase de comblement, comprenant les résidus de forge et le lot d'enclumes.

\section{UN NIVEAU DE FONCTIONNEMENT ET DES BATTITURES EN QUANTITÉ (FIG , 14)}

Les niveaux sous-jacents composés exclusivement de résidus de forge (scories, petits fragments de terre cuite, parois de foyer, petits blocs granitiques) semblent correspondre au fonctionnement 


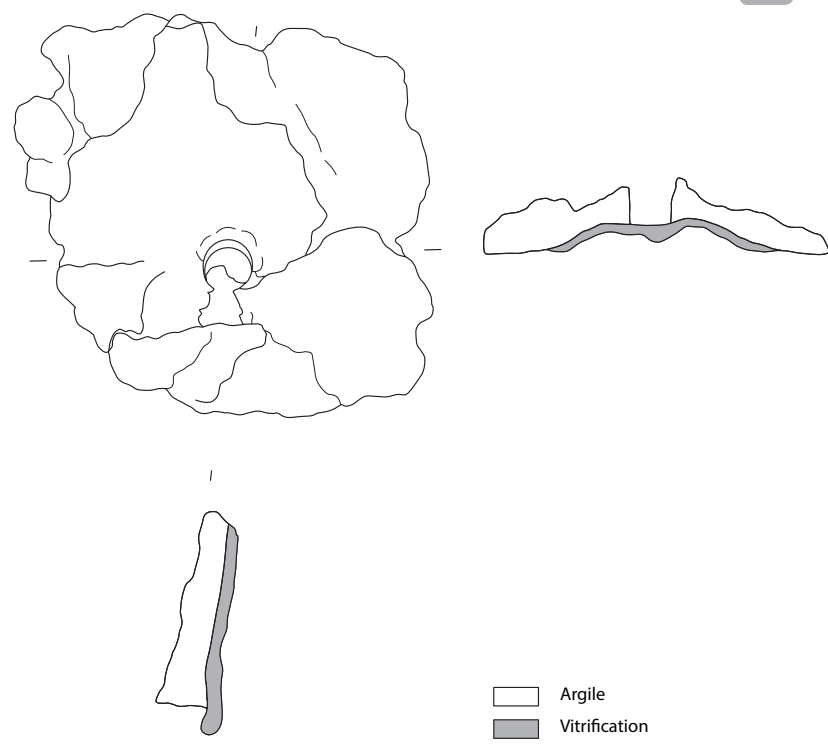

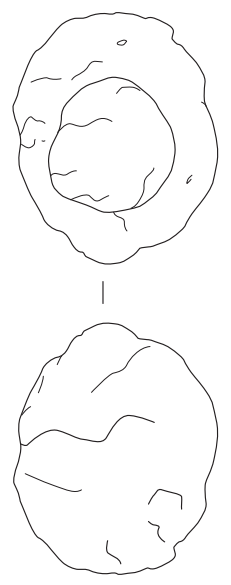

6259-CIN-1014-17-011
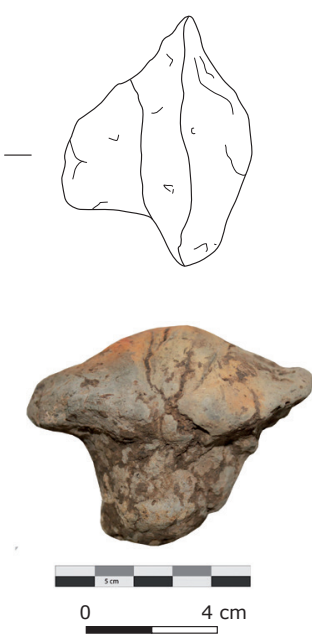

Figure 13

1. Paroi de four en argile cuite avec des traces de vitrification sur la face interne et un évent (fosse 1014, us 15).

2. Bouchon en terre cuite provenant de la fosse 1014.

(c) DAO : Ingrid Turé, Inrap.

Figure 14 : refus de tamis d'un litre de sédiment prélevé dans I'US.16 dans la fosse St.1014.

Parfois jusqu'à 180 gr de battitures par litre.

(C) cliché P. Clerc, Inrap.

d'activités de post-réduction. Les quelques fragments de scories dont la nature peut évoquer des rebuts de réduction sont en quantité trop faible pour pouvoir attester d'une telle activité sur le site (5 fragments pour $558 \mathrm{gr}$ ).

Parmi les scories de post-réduction, les culots de forge, entiers (282 individus) ou fragmentés, sont la catégorie la mieux représentée. Chacun de ces rebuts, de forme plus ou moins hémisphérique, est le produit d'une seule phase du travail

de I'atelier. L'échantillonnage systématique et le tamisage ont permis de quantifier les résidus archéo-métallurgique dont des battitures $(30 \mathrm{~kg})$ de toutes sortes et de toutes les tailles (granulaires, globulaires, lamellaires, billes, etc.) mêlées aux scories. Ces résidus proviennent probablement du nettoyage du niveau de sol de l'atelier (non conservé) en périphérie des enclumes. Les chutes de métal sont rares.

\section{ANALYSES MACROSCOPIQUES DES RÉSIDUS DE LA FORGE (FIG. 15)}

Au total, ce sont près de $70 \mathrm{~kg}$ de scories qui ont été récoltés lors de la fouille, principalement dans le silo 1003 (fouillé de moitié : $23,2 \mathrm{~kg}$ ) et dans la fosse atelier $1014(42,9 \mathrm{~kg})$. Ces déchets sont presque exclusivement des produits issus du fer, de l'allumage à l'extinction du foyer de forge. Selon l'activité en cours (épuration du fer brut, fabrication d'objet, recyclage...) la nature des déchets produits va varier. À Weyersheim, on peut distinguer quatre groupes principaux en fonction de la nature du matériau qui les constitue. Le groupe des scories ferreuses (SFR) est le mieux représenté puisqu'il rassemble plus de $67 \%$ des culots présents sur le site. Ils sont d'une couleur grise à rouille et sont magnétiques, ce qui témoigne de la présence de fer-métal enfermé dans la masse. Il se décline en 2 types : les scories denses (SFR1) et les scories aérées (SFR2). Les scories grises denses (SGD) sont le deuxième groupe distingué. Il rassemble des pièces de couleur sombre et d'une texture compacte et représente $22 \%$ des culots de forge. 
Figure 15

Répartition globale des différents facies de scories.

\begin{tabular}{|c|c|c|c|c|}
\hline Structure & SAS & SFR & SGD & SGC \\
\hline 1002 & & 2 & & 1 \\
\hline 1003 & 10 & 57 & 17 & 5 \\
\hline 1012 & & 1 & & \\
\hline 1014 & 6 & 128 & 45 & 8 \\
\hline 1081 & & 2 & & \\
\hline Total & 16 & 190 & 62 & 14 \\
\hline
\end{tabular}

Nombre de scorie de forge entière par type et par contexte.

\begin{tabular}{|c|c|c|c|c|}
\hline Structure & SAS & SFR & SGD & SGC \\
\hline 1014 & 6 & 128 & 45 & 8 \\
\hline
\end{tabular}

Nombre de scorie de forge entière par type de la fosse 2014.

\begin{tabular}{|c|c|c|c|c|}
\hline Structure & SAS & SFR & SGD & SGC \\
\hline 1003 & 10 & 57 & 17 & 5 \\
\hline
\end{tabular}

Nombre de scorie de forge entière par type du silo 2003.
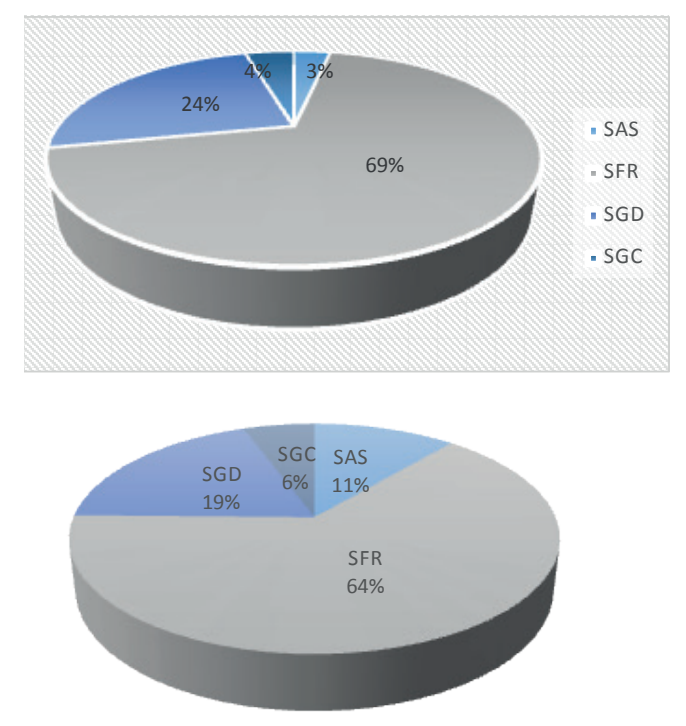

$\because \mathrm{SAS} \backsim \mathrm{SFR} \backsim \mathrm{SGD} \backsim \mathrm{SGC}$

Les scories argilo-sableuses (SAS) sont également divisées en deux types : d'aspect vitreux et de couleur claire (SAS1) et plus denses et plus sombres (SAS2). Seuls 6 culots de forge présentent ce faciès dans l'échantillonnage. Toutefois, une dizaine de coulures de scories indépendantes sont du même matériau (6\%). Le dernier groupe (SGC) rassemble un ensemble de 14 scories grises et charbonneuses (5\%)

La diversité des faciès de scories en culots montre que plusieurs étapes de la chaîne opératoire de la forge ont été pratiquées sur le site, même si les activités produisant des scories SFR sont largement majoritaires.

Au final, la masse des scories de forge des deux structures 1003 et 1014, en ajoutant les éléments contenus dans la seconde moitié du silo, serait d'environ $90 \mathrm{~kg}$. En prenant en compte les battitures et autres micro-déchets de forge, on peut estimer le poids total des déchets compris dans ces 2 structures à $130 \mathrm{~kg}$. Ces valeurs placent le site parmi les plus riches en données pour l'Europe (site de Sévaz en Suisse : $120 \mathrm{~kg}$; Bragny-sur-Saône : $400 \mathrm{~kg}$; Lyon-Vaise : $139 \mathrm{~kg}$ [28]).

[28] FILIPPINI 2015, p. 180-181.

\section{ANALYSES MÉTALLOGRAPHIQUES (FIG. 16)}

Les analyses au microscope optique ont été effectuées au laboratoire Métallurgies et Cultures IRAMAT - URM5060 - CNRS -UTBM par Marion Berranger assistée de Patrick Clerc. À partir d'un échantillonnage représentatif des déchets les plus fréquents l'étude au microscope métallographique a porté sur quinze culots de forge et six chutes métalliques (voir pour la méthodologie Berranger 2014 : 46-47). Les résultats mettent en évidence la pratique de l'intégralité de la chaîne opératoire de post-réduction.

Les cinq culots analysés provenant du silo 1003 sont tous caractéristiques d'une phase d'épuration primaire de masses brutes de réduction (fig. 16A). La proportion de métal perdu au sein des culots est très importante (8 à 14\% des surfaces). Il s'agit de gros fragments de métal mesurant plusieurs centimètres de côté, aux surfaces irrégulières et qui présentent un grand nombre de porosités et de replis non ou peu déformés. Les teneurs en carbone oscillent généralement autour de $0,8 / 0,7 \% \mathrm{C}$ ce qui en faisaient des produits durs, mais parfaitement forgeables. Ces fragments cassants, du fait de leur dureté, se sont détachés de masses de métal brut durant le processus d'épuration. Pour la fosse 1014, I'analyse de dix culots (fig. 16B) et de quatre chutes métalliques 


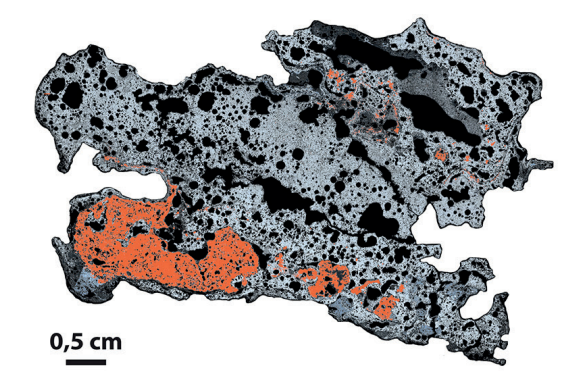

A. Culot SGD 1003-4-9

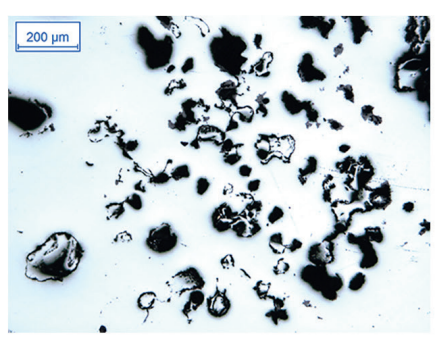

Replis et porosités dans le métal

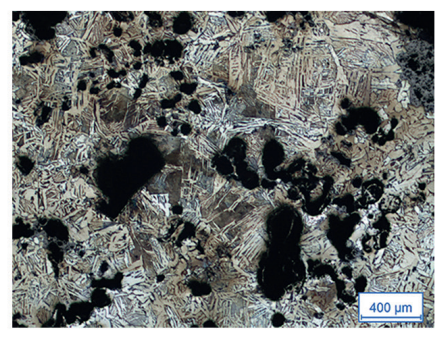

Acier à $0,5 / 0,6 \% C$

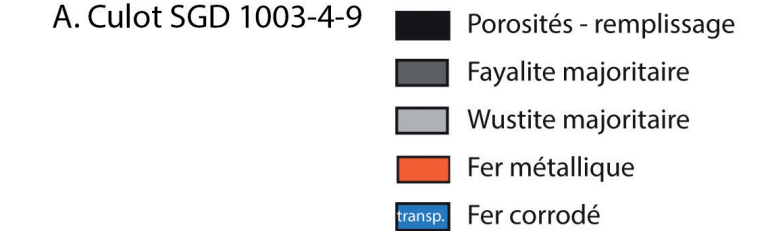

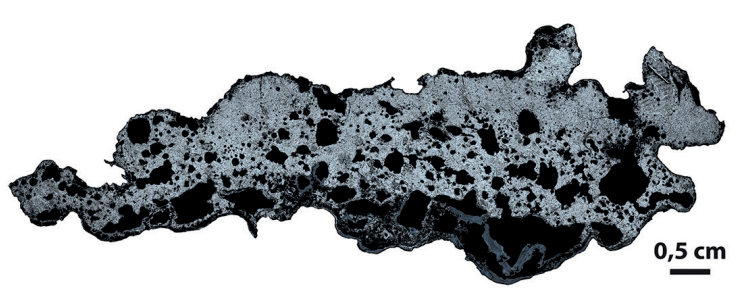

B. Culot SFR2 1014-15-23

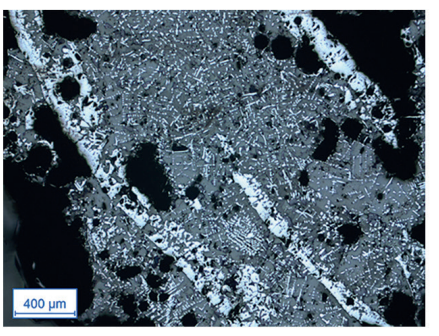

Battitures plates et globulaires dans la matrice base silice

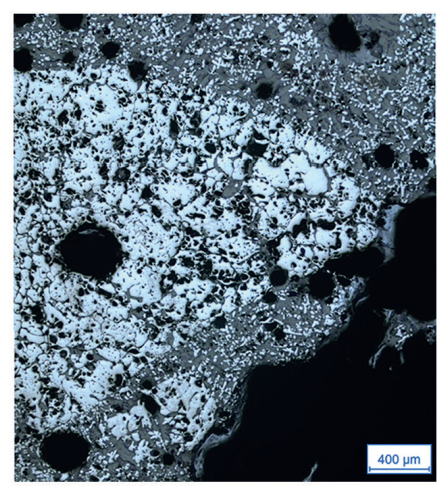

DAO et clichés : M. Berranger - LMC - CNRS

Figure 16

Observations métallographiques sur deux culots issus des fosses 1003 (A) et 1014 (B). À gauche: section polie légendée. À droite : clichés micro-photographiques.

témoigne des étapes de compactage à un stade ultérieur et surtout des étapes de mise en forme d'objets. Dans les culots, la proportion de métal est plus faible que précédemment (inférieure à $1 \%$ des sections) et les surfaces des éclats sont fortement aplanies. Ces culots ont été formés durant des étapes de forte oxydation à chaud ayant entraîné d'abondantes pertes en oxydes (battitures plus ou moins dissoutes). Plusieurs culots se caractérisent par une stratification correspondant à des séquences distinctes d'une même opération technique.

Les déchets métalliques correspondent à des produits assez travaillés, constitués d'acier trempable, aux surfaces fortement déformées et bien épurées. Ces indices permettent de reconnaître le travail d'artisan(s) réalisant des tâches récurrentes et probablement spécialisées, et d'identifier deux types d'activités distinctes, spatialement séparées.

[29] MICHLER et alii, à paraître.

[30] Nous pouvons ajouter à ce lot 73 fragments indéterminés de granite, d'une masse totale de 17,6 kilogrammes, extraits des structures 1003 et 1014 . Tandis que la structure 1003 a livré 9 blocs (2,1 kilogrammes),

\section{OUTILS LITHIQUES LIÉS À LA SPHÈRE MÉTALLURGIQUE}

Il s'agit principalement des enclumes, des percuteurs et des outils d'abrasion pour les polissoirs et les aiguisoirs. Une publication à paraître développera cet aspect [29].

Le lot de 16 blocs de granite, tous brisés, totalisant 206,9 kilogrammes [30], a été choisi parmi de gros blocs roulés (fig. 17).

Les multiples stigmates, sur les faces et les arêtes, supposent différentes étapes de traitement et une utilisation de différents outils à percussion lancée plurifonctionnels [31] (fig. 17, 2 et 3 ). Peu d'enclumes sont connues pour cette période. Citons celle de Sévaz/Tudinges en Suisse [32] sur laquelle est visible une cupule d'origine thermo-mécanique proche de nos surfaces concaves. Pour le $\mathrm{II}^{\mathrm{e}}$ siècle 
Figure 17

1. Dénombrement (graphique radar) des types de surfaces actives, des types d'impacts et des aspects de surfaces présents sur les enclumes découvertes ;

2. Bloc 1 de la fosse 1014. Cette enclume porte une vaste surface active plane, mais interrompue par une cassure ;

3. Bloc 1 de la fosse 1014. Vue avec lumière rasante de la surface active et des impacts nombreux.

4. Graphique des variables issues de l'analyse des correspondances multiples.

(c) cliché P. Clerc, retouche et DAO : M. Michler, Inrap, S. Badey, Inrap.

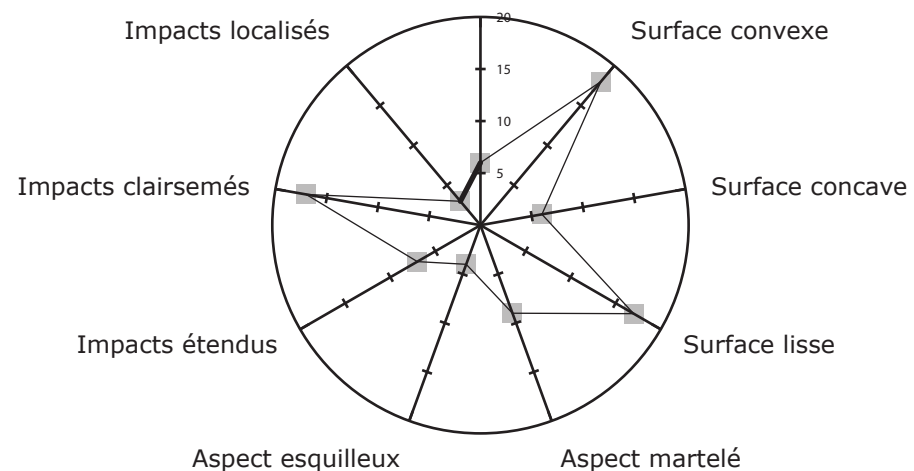

1

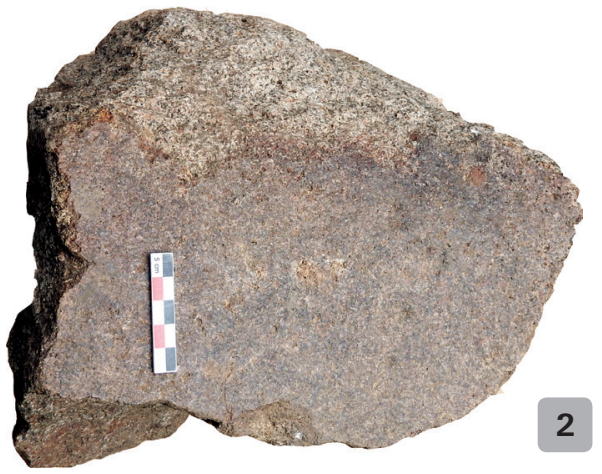

3
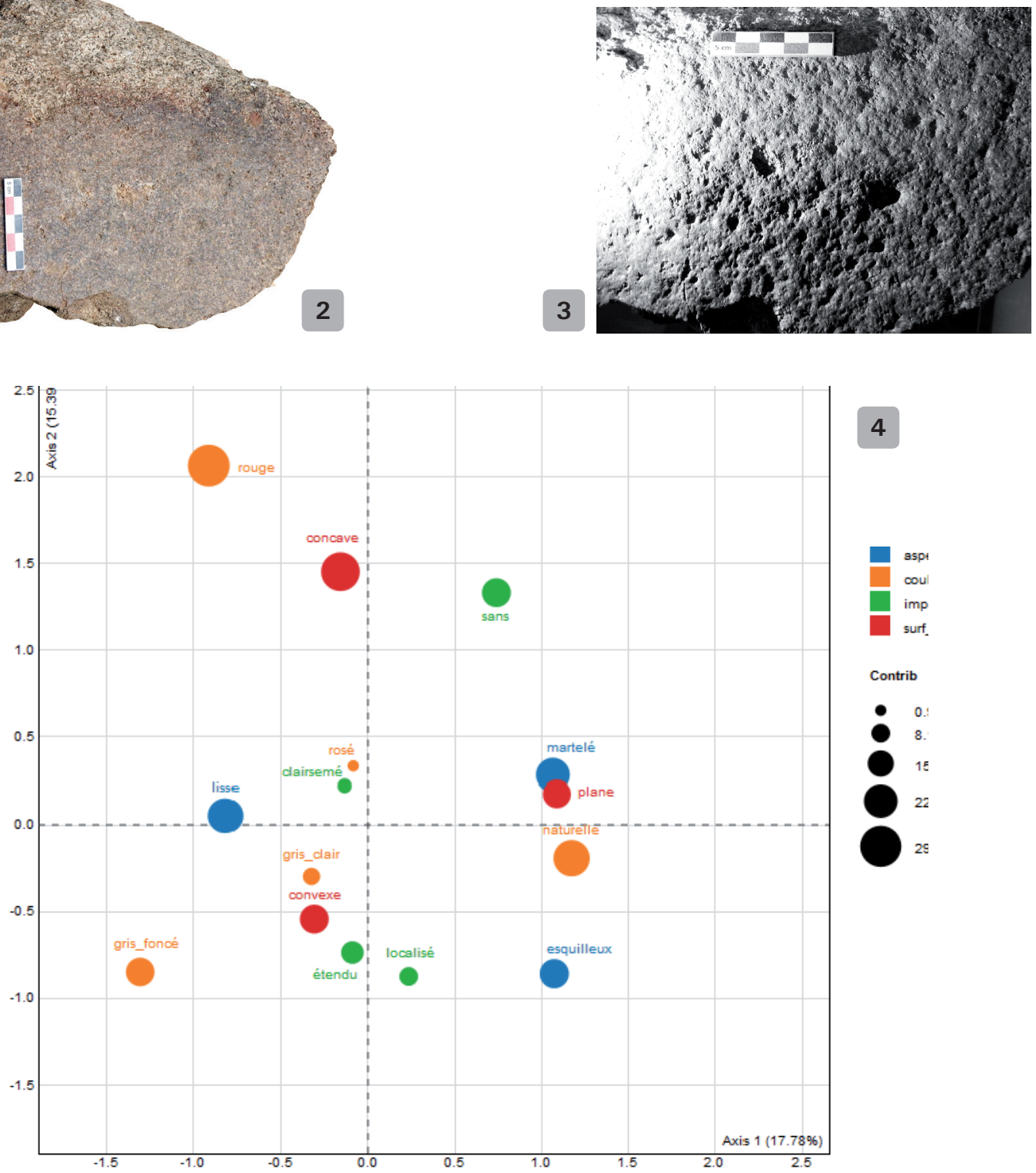
av. J.-C. citons celle de la forge de Paule en Côte d'Armor [33]. Les exemplaires sont aussi rares pour La Tène finale (enclume de Rochères dans I'Aisne, ou de Neuville-sur-Sarthe [34]).

Ces blocs de granite proviennent très probablement de la vallée de la Fecht, à 100 kilomètres au sud-ouest du site de Weyersheim. Cette roche plutonique semble avoir été choisie pour ses propriétés mécaniques. Sa texture est tenace, et par conséquent plus résistante à la propagation d'une fissure [35].

Près de 30 surfaces actives ont été observées sur les galets (fig. 17, 1). Vu l'aspect inédit de cette découverte d'enclume, et en l'absence d'analyses spécifiques sur ce type d'objets, nous avons enregistré plusieurs variables qui nous semblent pertinentes. Ces surfaces sont soit planes, convexes ou concaves, soit lisses, martelées ou esquilleuses. Les impacts peuvent être couvrants, clairsemés, localisés sur de petites zones ou absents. L'absence d'impact ne signifie pas l'absence d'utilisation comme la mise en forme de tôles, peu perceptible. Une coloration rougeâtre et rosée, peut-être induite par le travail de forge, marque également certaines surfaces. La démarche d'analyse statistique a été présentée lors du colloque de Belfast [36] et est disponible dans un rapport de recherche [37].

En définitive cinq groupes de surfaces d'enclumes ont été retenus suite à l'analyse statistique multivariée (fig. 23). Le graphique des variables issu de l'Analyse des Correspondances Multiples (fig. 17, 4) permet de résumer le mieux possible I'information relative aux variables et leurs combinaisons. Soulignons que le plan formé par les deux premiers facteurs ne représente que $33,17 \%$ de I'information, ce qui amène à rester prudent sur les conclusions présentées ci-dessous. Remarquons également que même si la variable impact (sans, clairsemé, étendu, localisé) à des contributions moindres que les autres, il nous a semblé important de la conserver au vu de son importance dans la caractérisation des enclumes.

- La classe 1 regroupe les surfaces actives d'aspect lisse et de couleur grise (clair ou foncé). En outre ces surfaces ont une morphologie convexe (sauf une) et des impacts clairsemés pour la majorité d'entre elles (sauf 3 ). Ces critères nous conduisent à penser que les pièces lithiques ont été employées dans le cadre d'une phase d'élaboration, peut-être pour l'emboutissage de plaques métalliques.

- La classe 4 réunit les surfaces actives martelées (sauf une) et qui présentent des impacts clairsemés (sauf 2). Elles sont soit de couleur naturelle soit gris clair. Par contre elles peuvent présenter une morphologie plane (4) convexe (3), ou concave (2). L'aspect martelé et polymorphe des surfaces actives suggère l'emploi de ces enclumes dans la phase d'épuration. Remarquons également qu'aucune coloration ne teinte la roche. D'après la classification ascendante hiérarchique, cette classe pourrait être divisée en deux groupes. Mais pour le moment, par manque d'éléments de comparaison, cette observation ne dégage pas d'informations pertinentes.

- La classe 3 rassemble les surfaces actives lisses (sauf une) et de couleur rosée. En revanche les surfaces sont planes (2), concaves (1) ou convexes (2) et peuvent présenter tous les types d'impact.

- La classe 5 concentre les surfaces actives convexes, d'aspect esquilleux et de couleur naturelle. Elles comportent des impacts localisés, étendus ou absents.

- La classe 2 assemble les surfaces actives lisses et de couleur rouge. De plus elles peuvent être concaves ou convexes et présenter des impacts clairsemés ou absents.

L'observation attentive des critères regroupés dans les classes 3,5 et 2 permet de nuancer l'organisation de la phase d'élaboration. Tandis que la classe 5 enregistre des marques esquilleuses sur un support plutôt convexe de couleur naturelle, indiquant une frappe plus violente, les deux autres classes présentent des stigmates presque identiques : impacts variés sur un support lisse et polymorphe. Seule la coloration de la surface rosé et rouge - nous indique une légère nuance de chauffe. Ce type de nuance a été observé lors de la chauffe progressive d'échantillons de granite gris réalisée en laboratoire [38]. Les analyses montrent qu'une teinte rougeâtre accompagnée d'un changement de texture apparaît avec l'augmentation de la température, entre $400^{\circ} \mathrm{C}$ et $600^{\circ} \mathrm{C}$.

Tandis que les percuteurs ont pu servir au façonnage et au modelage de pièces métalliques (planage des tôles 1058-1), les polissoirs en grès et aiguisoirs en quartzite (pour les cupro alliages) semblent dédiés à la finition d'objets métalliques.

[33] MeNEZ et alii, p. 224 et 231.

[34] JODRY 2015.

[35] FRONTEAU \& BOYER 2011, p. 113.

[36] MICHLER et alii à paraître.

[37] BADEY 2016.

[38] Vasquez et alii, 2016. 


\section{Hierarchical Clustering}
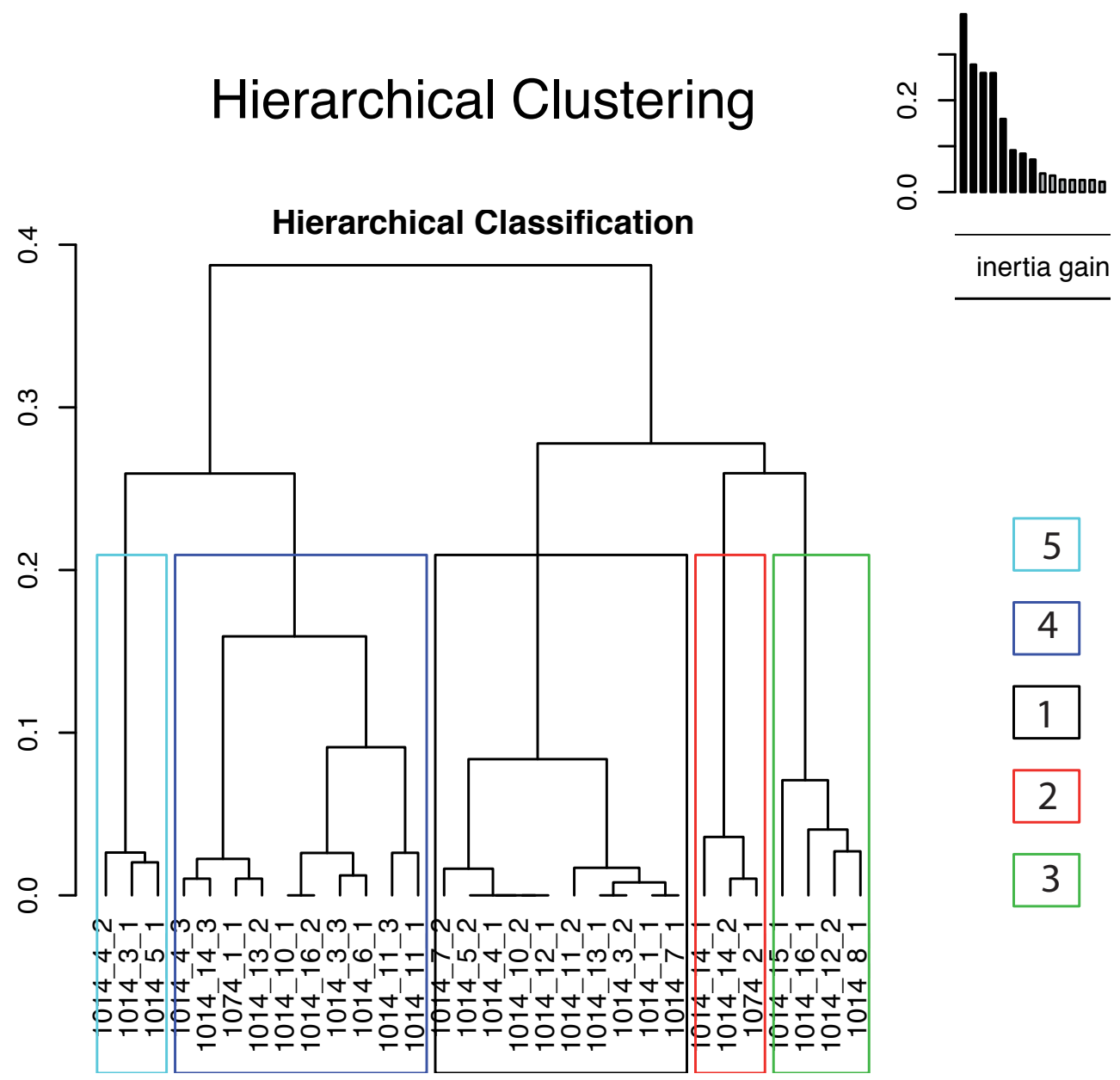

Figure 18

3

Dendrogramme

issu du

classement

ascendant

hiérarchique.

(C) Sylvain

Badey, Inrap.

\section{CONCLUSIONS}

À I'heure actuelle l'activité métallurgique sur le site de Weyersheim «Les Hauts de la Zorn », constitue un cas unique en Alsace de par la quantité hors-norme de déchets métallurgiques découverts $(110 \mathrm{~kg})$.

L'analyse des fosses circulaires 1003 et 1014 suggère un fonctionnement probablement synchrone. La fosse 1014 a livré le plus d'informations, avec la mise en évidence d'un premier niveau de fonctionnement et deux couches d'abandon de I'atelier [39]. Quant aux enclumes elles portent différents types d'impacts et de surfaces actives correspondant probablement à deux types de travail de la forge d'épuration et d'élaboration. L'étude des culots et déchets métalliques permet d'identifier les mêmes types d'activités. Lors de la fouille de la fosse 1014, le sédiment rempli de déchets (battitures, restes de foyers) a été prélevé. Seule une partie de ces restes a été étudiée pour le moment. Morphologiquement, la fosse 1014 présente les mêmes caractéristiques que celles où sont implantés des ateliers contemporains. Deux fosses circulaires sont ainsi connues sur le site de Sévaz [40] (fig. 11, 2) ou une fosse ronde rue du Docteur Horand à Lyon [41].

L'examen d'une partie des culots suppose la réalisation de deux activités distinctes : épuration d'un métal brut ou peu épuré (st. 1003) et mise en forme d'objets au niveau de l'atelier (st. 1014). En retenant I'hypothèse de contemporanéité, la localisation de ces activités dans une même zone montre une organisation précise et complémentaire des ateliers de forgeage. Dans le cas d'une succession assez courte dans le temps, il faudrait souligner l'emprise forte de l'activité métallurgique dans ce secteur du site. Il manque les traces de l'atelier d'épuration d'où proviennent les culots rejetés dans le silo 1003. Ce dernier se trouve probablement à proximité, mais hors emprise de la fouille. Une prospection géophysique serait à engager pour localiser les restes de cet atelier plus à l'ouest dans les parcelles encore en culture.

[39] Cf. supra.

[40] MAUVILLY et alii, 2007, fig. 2, structures 1 et 2. [41] FiLiPINI 2015, p. 43. 
Soulignons qu'aucun objet achevé ne provient de la fosse 1014 qui n'a livré que des chutes, sous forme de barres, tiges ou tôle. L'herminette, la lance et le ciseau proviennent de silos situés dans la zone d'ensilage et au nord. Leur fabrication sur place n'est pas établie et la question de leur origine reste ouverte. Quoi qu'il en soit leurs formes s'apparentent avec celles d'exemples connus à la même période dans le domaine hallstattien centre-occidental.

Afin de replacer le site de Weyersheim dans son contexte régional, un tableau synthétique, faisant le bilan des découvertes contemporaines en Alsace a été réalisé (fig. 19). Sur ces sites les scories semblent essentiellement résulter d'une activité de forge. Dans certains cas, l'imprécision de l'identification ne permet pas de différencier les déchets de réduction, d'épuration ou d'élaboration. Une reprise des données semble nécessaire.

Une grande majorité des sites recensés présente à la fois des vestiges du travail du fer et des alliages cuivreux. C'est également le cas à Weyersheim. Cette association est courante pour cette période entre le Hallstatt final et La Tène ancienne [42].

Weyersheim se distingue par contre clairement des autres sites par la quantité importante de matériel lié à la métallurgie, tous types confondus (sauf pour les creusets). La découverte d'un niveau de fonctionnement d'atelier constitue d'ailleurs une nouveauté dans la région. Le second ensemble important correspond au site d'Entzheim-Geispolsheim fouillé sur près de sept hectares cumulés en 2006 et 2008-2009. Sur ce site, les restes liés à la métallurgie sont majoritairement en position secondaire comme c'est le cas pour les autres petits sites mentionnés.

Soulignons également le fait que ces traces d'activités métallurgiques se situent toujours à proximité d'une zone d'ensilage, plus rarement à proximité d'un habitat identifié. Le cas de l'atelier isolé est pour le moment inconnu. L'association entre activités métallurgiques et stockage de denrées en silo est particulièrement notable à Weyersheim. On peut même ici évoquer une centralisation de la production agricole au vu du nombre de silos identifiés (une cinquantaine). Ce lien entre métallurgie et zone de stockage a déjà été mis en évidence et étudié en Lorraine à partir des sites de Gondreville «ZAC de la Roseraie et Velaine-en-Haye » et «ZAC Herbue Chalin » [43] situés à proximité de I'habitat fortifié de la «Cité d'Afrique » de Messein. Dans ce dernier cas, un lien de dépendance entre I'habitat privilégié et les établissements ruraux de type fermes-greniers est envisagé, de manière concomitante au contrôle de la production du fer [44].

Plus largement, au niveau national et européen, les synthèses récentes sur le sujet [45] soulignent le nombre limité de gisements à vocation métallurgique (23 recensés dans la thèse $d^{\prime} A$. Filippini) et la faible proportion de déchets retrouvés. Quelques ensembles font exception par la masse de scories présentes tels celui de Bragnysur-Saône « Sous-Moussières » [46] qui livre plusieurs centaines de kilogrammes de déchets. Le site de Sévaz «Tudingues » en Suisse est l'un des rares qui puisse être comparé à Weyersheim par les proportions similaires de déchets de travail du fer (120 kg de scories [47]). Néanmoins, ces sites se distinguent de celui de Weyersheim par la présence de céramique tournée et/ou d'objets d'importation évoquant un statut social élevé des habitants. À Weyersheim la céramique tournée est absente, mais cela pourrait peut-être être lié à la chronologie, cette céramique apparaissant plutôt à La Tène $\mathrm{A} 1$ et étant très peu représentée à la phase antérieure [48]. La datation du site étant assez large (problème du plateau du Hallstatt pour les datations ${ }^{14} \mathrm{C}$ ) cette hypothèse n'est pas à exclure.

L'observation de la carte des principaux sites datés entre le Hallstatt D3 et La Tène ancienne présentant des traces de métallurgie dans le nord Alsace (fig. 2 et fig. 19) montre une concentration d'une vingtaine de kilomètres de diamètre constitué des sites d'Ettendorf, Mittelhausen, Souffelweyersheim, Brumath et Weyersheim, situé le plus haut au nord). À I'heure actuelle, de telles découvertes n'ont pas été observées au delà d' Haguenau. Il reste encore à déterminer comment la production d'objets en fer était organisée du point de vue régional dans le complexe hallstattien occidental. En cette fin de premier âge du Fer, la concentration du pouvoir et des richesses aux mains d'une élite sociale, occupant le plus souvent des centres fortifiés (Illfurth, « Britzgyberg » et Breisach, « Münsterberg ») est à prendre en compte. Dans la forêt de Haguenau, de riches sépultures sont connues à la fin du Hallstatt, mais un net appauvrissement est perceptible au

[42] FILIPPINI 2015.

[43] LeRoY \& CABBoÏ (dir), 2013.

[44] BERRANGER et alii 2017.

[45] FILIPPINI 2015.

[46] FLOUEST 2007.

[47] MAUVILLY et alii 2007.

[48] AdAM et alii 2011. 
Figure 19

Inventaire des sites alsaciens ayant livré des indices de travail du fer.

(C) M. Michler, Inrap.

\begin{tabular}{|c|c|c|c|c|c|c|}
\hline \multirow{3}{*}{$\begin{array}{c}\text { Bruebach «Rennwasen» } \\
\text { et «Auf dem Burner } \\
(\text { H.-R.) }\end{array}$} & \multicolumn{2}{|c|}{ Culots de forge/scories } & \multicolumn{2}{|c|}{ Creusets/Moules } & \multicolumn{2}{|c|}{ Parois de four vitrifiées } \\
\hline & Présence & $x$ & Présence & $x$ & Présence & $x$ \\
\hline & NR & $?$ & NR & & NR & \\
\hline \multirow{4}{*}{$\begin{array}{l}\text { Datation : Ha D3-LT A1 } \\
\text { Type de site : silos prospection/ } \\
\text { fouille } \\
\text { Surface en } \mathrm{m}^{2}: \text { / }\end{array}$} & Masse $(\mathrm{kg})$ & $?$ & Masse $(\mathrm{kg})$ & & Masse $(\mathrm{kg})$ & \\
\hline & \multicolumn{2}{|c|}{ Battitures } & \multicolumn{2}{|c|}{ Chute de métal } & \multicolumn{2}{|c|}{ Bibliographie } \\
\hline & Présence & & Présence & & \multirow{2}{*}{\multicolumn{2}{|c|}{ Koenig et al 2005}} \\
\hline & Infos & & NR chute & & & \\
\hline
\end{tabular}

\begin{tabular}{|c|c|c|c|c|c|}
\hline \multirow{3}{*}{$\begin{array}{l}\text { Brumath Lotissement Manet } \\
\text { (B.-R.). }\end{array}$} & \multicolumn{2}{|c|}{ Culots de forge/scories } & Creusets/Moules & \multicolumn{2}{|c|}{ Parois de four vitrifiées } \\
\hline & Présence & fragments & Présence & Présence & Possible tuyère ? \\
\hline & NR & & NR & NR & \\
\hline \multirow{4}{*}{$\begin{array}{l}\text { Datation : Ha D1-D2 } \\
\text { Type de site : petit habitat } \\
\text { ouvert } \\
\text { Surface en } \mathrm{m}^{2} \text { : env. } 10000\end{array}$} & Masse $(\mathrm{kg})$ & & Masse $(\mathrm{kg})$ & Masse $(\mathrm{kg})$ & \\
\hline & \multicolumn{2}{|c|}{ Battitures } & Chute de métal & \multicolumn{2}{|c|}{ Bibliographie } \\
\hline & Présence & & Présence & \multirow{2}{*}{\multicolumn{2}{|c|}{$\begin{array}{l}\text { Mentele, Plouin, Guillaume } 2005, \\
\text { p. } 158 \text {, pl. } 2,19\end{array}$}} \\
\hline & Infos & & NR chute & & \\
\hline
\end{tabular}

\begin{tabular}{|c|c|c|c|c|c|c|}
\hline \multirow{3}{*}{$\begin{array}{l}\text { Ettendorf «Gaentzbruch» } \\
\text { (B.-R.) }\end{array}$} & \multicolumn{2}{|c|}{ Culots de forge/scories } & \multicolumn{2}{|c|}{ Creusets/Moules } & \multicolumn{2}{|c|}{ Parois de four vitrifiées } \\
\hline & Présence & $x$ & Présence & $x$ & Présence & $x$ \\
\hline & NR & 8 & NR & 1 & NR & 11 \\
\hline \multirow{4}{*}{$\begin{array}{l}\text { Datation : Ha D2-LT B1 } \\
\text { Type de site : aire d'ensilage } \\
\text { Surface en } \mathrm{m}^{2}: 2000\end{array}$} & Masse $(\mathrm{kg})$ & 1,65 & Masse $(\mathrm{kg})$ & 0,013 & Masse $(\mathrm{kg})$ & \\
\hline & \multicolumn{2}{|c|}{ Battitures } & \multicolumn{2}{|c|}{ Chute de métal } & \multicolumn{2}{|c|}{ Bibliographie } \\
\hline & Présence & $x$ & Présence & $x$ & \multirow{2}{*}{\multicolumn{2}{|c|}{$\begin{array}{c}\text { Peytremann, } 2004, \text { p. } 25-26 \text {, } \\
\text { fig. } 15\end{array}$}} \\
\hline & Infos & 0,854 & NR chute & $1 /$ & & \\
\hline
\end{tabular}

Geispolsheim «Schwobenfeld» (B.-R.)

/ Entzheim «in der Klamm»

Datation : Ha D3-LTA et LT A-B1 Type de site : aire d'ensilage avec traces d'habitat

Surface en $\mathrm{m}^{2}: 7$ ha au total

\begin{tabular}{|c|c|c|c|c|c|}
\hline \multicolumn{2}{|c|}{ Culots de forge/scories } & \multicolumn{2}{|c|}{ Creusets/Moules } & \multicolumn{2}{|c|}{ Parois de four vitrifiées } \\
\hline Présence & $X$ & Présence & $X$ & Présence & X \\
\hline NR & 32 & NR & & NR & 13,5 \\
\hline Masse $(\mathrm{kg})$ & 14 & Masse $(\mathrm{kg})$ & & Masse $(\mathrm{kg})$ & \multicolumn{2}{|c|}{ Bibliographie } \\
\hline \multicolumn{2}{|c|}{ Battitures } & \multicolumn{2}{|c|}{ Chute de métal } & \multicolumn{2}{|c|}{ Landolt 2007 } \\
\hline Présence & $X$ & Présence & $X$ & \multicolumn{2}{c|}{ X } \\
\hline Infos & dans 55 str. & NR chute & 1 & \multicolumn{2}{c}{} \\
\hline
\end{tabular}

Illfurth «Britzgyberg», «Buergelen», «Naegelberg» (H.-R.)

Datation : Ha D3-LT A1

Type de site : site de hauteur et habitat

Surface en $\mathrm{m}^{2}$ : plus de 4000

\begin{tabular}{|c|c|c|c|c|c|}
\hline \multicolumn{2}{|c|}{ Culots de forge/scories } & \multicolumn{2}{|c|}{ Creusets/Moules } & \multicolumn{2}{|c|}{ Parois de four vitrifiées } \\
\hline Présence & $x$ & Présence & $?$ & Présence & \\
\hline NR & & NR & & NR & \\
\hline Masse $(\mathrm{kg})$ & & Masse $(\mathrm{kg})$ & & Masse $(\mathrm{kg})$ & \\
\hline \multicolumn{2}{|c|}{ Battitures } & \multicolumn{2}{|c|}{ Chute de métal } & \multicolumn{2}{|c|}{ Bibliographie } \\
\hline Présence & & Présence & & \multirow{2}{*}{\multicolumn{2}{|c|}{ Adam et alii, 2011, p. 65-67 }} \\
\hline Infos & & NR chute & & & \\
\hline
\end{tabular}


Kutzenhouse lotissement Galgenstraenge IV (B.-R.)

Datation : âge du fer ? Type de site : silo, diag Surface en $\mathrm{m}^{2}$ : 1000

\begin{tabular}{|c|c|c|c|c|c|}
\hline \multicolumn{2}{|c|}{ Culots de forge/scories } & \multicolumn{2}{|c|}{ Creusets/Moules } & \multicolumn{2}{|c|}{ Parois de four vitrifiées } \\
\hline Présence & $\mathrm{X}$ & Présence & Présence & X \\
\hline NR & 2 & NR & & NR & 6 , orifice tuyère \\
\hline Masse $(\mathrm{kg})$ & 1,3 & Masse $(\mathrm{kg})$ & & Masse $(\mathrm{kg})$ & \\
\hline \multicolumn{2}{|c|}{ Battitures } & Chute de métal & \multicolumn{2}{|c|}{ Bibliographie } \\
\hline Présence & Présence & $X$ & \multicolumn{2}{|c|}{ Latron 2015 } \\
\hline Infos & NR chute & 2 & \multicolumn{2}{|c|}{} \\
\hline
\end{tabular}

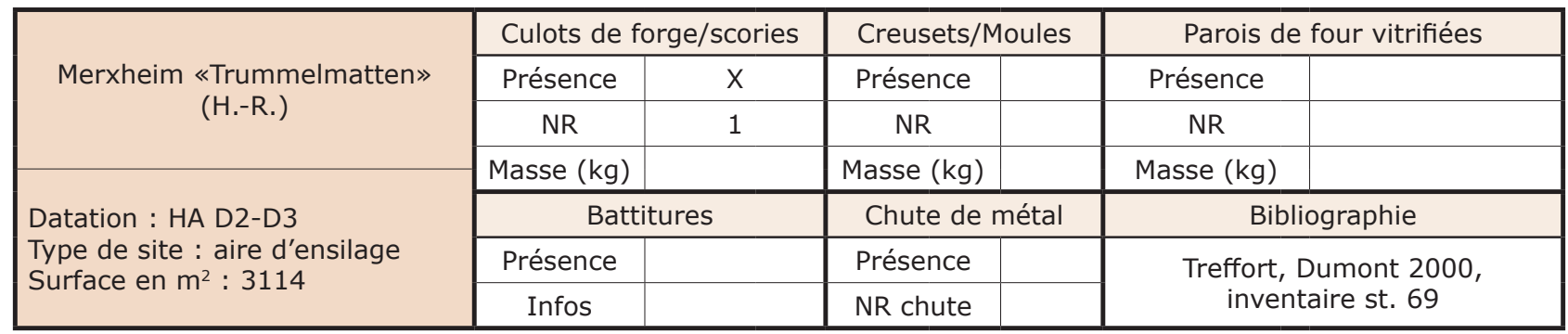

Mittelhausen «Liesbuehl / imbretter Weg»

(B.-R.)

Datation : LTA

Type de site : aire d'ensilage Surface en $\mathrm{m}^{2}: 5000$

\begin{tabular}{|c|c|c|c|c|c|}
\hline \multicolumn{2}{|c|}{ Culots de forge/scories } & \multicolumn{2}{|c|}{ Creusets/Moules } & \multicolumn{2}{|c|}{ Parois de four vitrifiées } \\
\hline Présence & $\mathrm{X}$ & Présence & $\mathrm{X}$ & Présence & X \\
\hline NR & 22 & NR & & NR & 0,99 \\
\hline Masse $(\mathrm{kg})$ & 0,574 & Masse $(\mathrm{kg})$ & 0,44 & Masse $(\mathrm{kg})$ & \multicolumn{2}{|c|}{ Bibliographie } \\
\hline \multicolumn{2}{|c|}{ Battitures } & \multicolumn{2}{|c|}{ Chute de métal } & \multicolumn{2}{|c|}{ Croutsch et al. 2015} \\
\hline Présence & $\mathrm{X}$ & Présence & \multicolumn{2}{|c|}{} \\
\hline Infos & $?$ & NR chute & \multicolumn{2}{c|}{} \\
\hline
\end{tabular}

\begin{tabular}{|c|c|c|c|c|c|c|}
\hline \multirow{3}{*}{$\begin{array}{l}\text { Souffelweyersheim } \\
\text { «Les Sept Arpents» } \\
\text { (B.-R.) }\end{array}$} & \multicolumn{2}{|c|}{ Culots de forge/scories } & \multicolumn{2}{|c|}{ Creusets/Moules } & \multicolumn{2}{|c|}{ Parois de four vitrifiées } \\
\hline & Présence & $x$ & Présence & $x$ & Présence & \\
\hline & NR & 2 & NR & 5 & NR & \\
\hline \multirow{4}{*}{$\begin{array}{l}\text { Datation : LT A2 } \\
\text { Type de site : petit habitat } \\
\text { ouvert } \\
\text { Surface en } \mathrm{m}^{2}: 5000\end{array}$} & Masse $(\mathrm{kg})$ & & Masse $(\mathrm{kg})$ & & Masse $(\mathrm{kg})$ & \\
\hline & \multicolumn{2}{|c|}{ Battitures } & \multicolumn{2}{|c|}{ Chute de métal } & \multicolumn{2}{|c|}{ Bibliographie } \\
\hline & Présence & $x$ & Présence & & \multirow{2}{*}{\multicolumn{2}{|c|}{$\begin{array}{l}\text { Lefranc et alii, 2008, p. 56-59, } \\
\text { pl. } 11, \text { n }^{\circ} 11\end{array}$}} \\
\hline & Infos & $?$ & NR chute & & & \\
\hline
\end{tabular}

Weyersheim Les Hauts de la Zorn (B.-R.)

Datation : Ha D3-LT A1 Type de site : aire d'ensilage avec rares traces $d$ 'habitat Surface en $\mathrm{m}^{2}$ : env. 10000

\begin{tabular}{|c|c|c|c|c|c|}
\hline \multicolumn{2}{|c|}{ Culots de forge/scories } & \multicolumn{2}{c|}{ Creusets/Moules } & \multicolumn{2}{|c|}{ Parois de four vitrifiées } \\
\hline Présence & $\mathrm{X}$ & Présence & $\mathrm{X}$ & Présence & $\mathrm{X}$ \\
\hline NR & & $\mathrm{NR}$ & 0,1 & NR & 30 \\
\hline Masse $(\mathrm{kg})$ & 67 & Masse $(\mathrm{kg})$ & & Masse $(\mathrm{kg})$ & \multicolumn{2}{|c|}{ Bibliographie } \\
\hline \multicolumn{2}{|c|}{ Battitures } & \multicolumn{2}{c|}{ Chute de métal } & \multicolumn{2}{|c|}{ Michler et alli, à paraître } \\
\hline Présence & $\mathrm{X}$ & Présence & $\mathrm{X}$ & \multicolumn{2}{|c|}{} \\
\hline Infos & $\begin{array}{c}35 \mathrm{~kg} \text { esti- } \\
\text { més }\end{array}$ & NR chute & 27 & \multicolumn{2}{|c|}{} \\
\hline
\end{tabular}

Wolfgantzen Deviation RN415 (H.-R.)

Datation : Ha D3-LT A1

Type de site : petit habitat ouvert

Surface en $\mathrm{m}^{2}: 7000$

\begin{tabular}{|c|c|c|c|c|}
\hline \multicolumn{2}{|c|}{ Culots de forge/scories } & \multicolumn{2}{|c|}{ Creusets/Moules } & \multicolumn{2}{|c|}{ Parois de four vitrifiées } \\
\hline Présence & $\mathrm{X}$ & Présence & Présence & \\
\hline NR & 1 & NR & NR & \\
\hline Masse $(\mathrm{kg})$ & & Masse $(\mathrm{kg})$ & Masse $(\mathrm{kg})$ & \multicolumn{2}{|c|}{ Bibliographie } \\
\hline \multicolumn{2}{|c|}{ Battitures } & Chute de métal & \\
\hline Présence & Présence & \\
\hline Infos & NR chute & \\
\hline
\end{tabular}


Hallstatt D3 alors qu'à La Tène A/B une prospérité persistante est à souligner [49]. Pour le moment, la proposition de voir dans le site du Hexenberg, proche de la forêt de Haguenau, au nord-est de Weyersheim, une possible résidence princière n'a pas été confirmée, les fouilles sur le site se rattachant plutôt au Bronze final et au Hallstatt C [50]. Il est possible que ce site de statut élevé se trouve ailleurs ou que le modèle des territoires princiers soit à nuancer dans ce secteur. Quoi qu'il en soit la région de Haguenau, de par sa position près du Rhin, reste un point de relais et de contrôle indéniable [51]. Les mêmes questionnements ont été évoqués pour la production primaire de fer et le rôle de cette activité dans le développement des centres de pouvoir au cours du premier âge du Fer [52]. Pour le moment, au vu de l'indigence des découvertes la question reste ouverte.

Concernant le type de matière première employée sur le site de Weyersheim, les analyses ont montré ce minerai était encore relativement brut. Son origine reste pour le moment inconnue. Il faut de plus noter l'absence d'indices de réduction connus dans la plaine rhénane. Du côté allemand, en ForêtNoire, il faut aller à une soixantaine de kilomètres à vol d'oiseau de Weyersheim, pour trouver un centre de production du fer, dans le secteur de Neuenbürg [53]. À la fin de la période hallstattienne et au début de La Tène, ce district minier compte plus de soixante-dix lieux de chauffe, dont des bas fourneaux, ce qui suggère une exploitation « proto-industrielle» du secteur.

Soulignons également que Weyersheim se trouve à une trentaine de kilomètres de la vallée de la Murg qui sépare deux sites de hauteur (Battert et
Neuenbürg) et correspondant à un passage entre Forêt-Noire et Alsace [54]. Ne négligeons pas non plus une origine depuis des sites de production locaux plus modestes. Les demi-produits bipyramidaux de fer connus à cette période et bien attestés en Alsace [55] ont également pu constituer une source d'approvisionnement. La découverte récente de plusieurs dizaines de demi-produits bipyramidés à Durrenentzen, non loin du site «princier» de Breisach, souligne l'importance de ce type d'objet dans la circulation du métal sous forme brute en Alsace au ve siècle av. J.-C. [56].

L'intérêt du site de Weyersheim est divers. En effet, rares sont les sites de ces périodes livrant de telles quantités de déchets de production du fer se rattachant de plus au traitement du fer depuis sa forme brute jusqu'à l'élaboration d'objets. L'association entre activités métallurgiques et zone de stockage de denrées agricoles ouvre également un large champ de réflexion sur les conditions de production et de diffusion de ces biens. Il reste à présent à mieux déterminer la place exacte et le rôle tenu par ces ateliers dans les réseaux de production et d'échange du métal en Alsace du Nord au début du second âge du Fer.

[49] Koenig \& LeGENDRE 1997, p. 90.

[50] Ibid, p. 90 ; LASSERRE et alii 2001.

[51] KoENIG \& LEGENDRE 1997, p. 90.

[52] DiSSER 2014, p. 500 ; DILLMANN et alii 2017.

[53] GASSMANN et alii 2006 et 2014.

[54] GenTNER 2016, p. 160.

[55] BERRANGER 2014.

[56] KUHNLE 2015. 
AChARD-Corompt, Nathalie \& Riquier, Vincent, 2013, Chasse, culte ou artisanat ? Les fosses «à profil en $Y-V-W \gg$. Structures énigmatiques et récurrentes du Néolithique aux âges des Métaux en France et alentours, Actes de la table ronde de Châlons-en-Champagne, 15/16 nov. 2010, Dijon (RAE suppl. 33).

Adam, Anne-Marie, Defressigne, Sylvie, Koenig, Marie-Pierre \& Lasserre, Marina 2011, avec la contribution d'Aurore Boyer, Hélène Delnef, Michaël Landolt, Suzanne Plouin, Murielle Roth-Zehner, \& Nicolas Tikonoff et la collaboration d'Inès Balzer, Gertrud Kuhnle, Jean-Michel Treffort \& Cécile Véber, La céramique d'habitat du Bronze final IIIb à La Tène B en Alsace et en Lorraine. Essai de typo-chronologie, Dijon (RAE suppl. 29).

Auxiette, Ginette, Baudry, Anna \& Meniel Patrice, 2010, « Une histoire de l'élevage dans l'ouest de la Normandie : les sites de Mondeville, Ifs, Fleury, Creully (Calvados) et les autres » dans Barral Philippe Dedet, Bernard Delrieu Fabien, Giraud Pierre, Le Goff Isabelle, Marion Stéphane, Villard-Le Tiec Anne (éd.), L'Âge du fer en BasseNormandie, Actes du XXXIII colloque international de I'AFEAF ; Caen, 20 au 24 mai 2009, Besançon (Annales littéraires de l'Université de Franche-Comté n 883 ; Série « Environnement, sociétés et archéologie »), p. 185-202.

BADEY, Sylvain, 2016, Analyse statistique des surfaces actives d'enclumes de Weyersheim, rapport de recherche, disponible en ligne : https://halshs.archives-ouvertes.fr/halshs-01436440.

BAUVAIS, Sylvain, 2008, «Du prestige à la proto-industrie : évolution des pratiques sidérurgiques au second âge du Fer dans le Nord du Bassin Parisien », The Arkeotek Journal 2, 4 ; www.thearkeotekjournal.org.

Benkert, Alain, Curdy, Philippe, Epiney-Nicoud, Claire, Kaenel, Gilbert, Mac Cullough, Fiona, Mauvilly, Michel \& RuffieuX, Mireille 2010, « Zentralisierungprozess und Siedlungdynamik in der Schweiz », dans D. Krausse (éd.), « Fürstensitze » und Zentralorte der frühen Kelten, Abschlusskolloquium des DFG-Schwerpunktprogramms 1171 in Stuttgart, 12.-15. Oktober 2009, Teil I, Landesamt für Denkmalpflege im Regierungspräsidium Stuttgart, Stuttgart (Forschungen und Berichte zur Vor- und Frühgeschichte in BadenWürttemberg 120), p. 79-118.

BerRANGer, Marion, 2014, Le fer, entre matière première et moyen d'échange, en France, du viI $I^{e}$ au I ${ }^{\text {er }}$ siècle avant J.-C. : approches interdisciplinaires, Dijon (Collection Art, Archéologie et Patrimoine).

Berranger, Marion, Zaour, Nolwenn, Leroy, Marc, Bauvais, Sylvain, Cabboï, Luisella \& Dunikowski, Christophe, 2017, «Organisation des productions sidérurgiques en Gaule (VII ${ }^{\mathrm{e}} \mathrm{I}^{\mathrm{er}}$ siècle av. J.-C.) : de la réduction du métal à l'élaboration des demi-produits » dans Production et proto-industrialisation aux âges du Fer, Actes du 39 e colloque de I'AFEAF tenu à Nancy du 14 au 17 mai 2015, Bordeaux (Mémoires 47), p. 301-334.

Bocquillon, Hervé, SAURel Marion, Dunikowski, Christophe \& Yvinec, Jean-Hervé, 2009 , «abitats et zones d'activités à Vrigny (Marne) à la fin du premier âge du Fer », dans Jan Vanmoerkerke (dir.), Le bassin de la Vesle du Bronze final au Moyen Age, Bulletin de la société archéologique champenoise 102, 2, p. 82-152.

Boutorlle, Linda, 2015, «Les techniques du dinandier de l'âge du Bronze : I'outillage en pierre spécifique à la déformation plastique des métaux », dans Nicolas Théophane et Boulud-Gazo Sylvie (éd.), Artisanats et productions à l'âge du Bronze, Actes de la journée de la Société Préhistorique Française, Nantes, 2011 (Séance de la Société Préhistorique Française 4), p. 83-96.

BROC, Émeline, 2011, Initiation aux méthodes de l'archéozoologie : Étude de deux sites du Bas-Rhin, Mittelhausen et Meistratzheim, Mémoire de Master, dactylographié, Université de Bourgogne, Dijon.

Croutsch, Christophe, 2012, Mittelhausen, Bas-Rhin, «Liesbuehl, Gimbretter Weg », construction de la LGV Est Européenne Tronçon H - Site 10-1. Structures domestiques et funéraires du Michelsberg et de La Tène, Rapport de fouille, PAIR.

Croutsch, Christophe, Landolt Michaël, Broc, Émilie, Fleischer, Félix, Mulot, Agathe, Nocus Noémie, Pélissier Amélie, Putelat Olivier \& Rousselet Oriane, 2015, « Le site de Mittelhausen «Liesbuehl / Gimbretter Weg » (Bas-Rhin, Alsace) : économie et environnement d'une aire d'ensilage de La Tène ancienne dans le Kochersberg », Revue Archéologique de I'Est 64, 2015, p. 111-160.

DABECK, Pierre, 2013, Weyersheim (Bas-Rhin), Rue de la Gare, lotissement «les Hauts de la Zorn », Indices de l'âge du Bronze et occupation du Hallstatt final/La Tène ancienne. Rapport de diagnostic, Inrap Ges.

DEFFRESSIGNE, Sylvie, 2017, «La place des productions au sein des habitats du bassin de Nancy entre le VIII ${ }^{\mathrm{e}}$ et le ve s. av. J.-C. », dans Marion Stéphane, Defressigne Sylvie, Kaurin Jenny \& Bataille Gérard (éd.), Production et proto-industrialisation aux âges du Fer, perspectives sociales et environnementales, XXXIXe colloque AFAEF, Nancy 14-17 mai 2015, Bordeaux (Mémoire 47, suppl. 14/2), p. 649-674.

Deffressigne, Sylvie \& LANdolt, Michaël, 2017, « L'évolution du stockage entre XI ${ }^{\mathrm{e}}$ et le III $^{\mathrm{e}}$ siècle av. J-C. dans les vallées de la Moselle, de la Meurthe et du Rhin », dans Marion, Stéphane, Defressigne Sylvie, Kaurin Jenny \& Bataille Gérard (éd.), Production et proto-industrialisation aux âges du Fer, perspectives sociales et environnementales, XXXIXe colloque AFAEF, Nancy 14-17 mai 2015,. Bordeaux (Mémoire 47, suppl. 14/2), p. 77-100.

Deffressigne, Sylvie \& Leroy, Marc, 2013 « L'organisation de la production du fer au cours de l'âge du Fer dans le bassin médian de la Moselle », dans Leroy Marc \& Cabboï Luisella (dir.), Les formes d'organisation de la production du fer en métallurgie anciennes. Systèmes de production et chaînes opératoires dans les ateliers de l'est du Bassin parisien de l'âge du Fer au haut Moyen Âge, rapport de PCR, p. 41-78. 
Deffressigne, Sylvie, Tikonoff, Nicolas, Boulanger-Boucher, Karine, Chaussé, Christine \& TesnierHermetey, Corinne, 2002, « Les gisements d'habitat de la fin du Premier âge du Fer à Gondreville-Fontenoy-surMoselle (54). Le stockage intensif et ses conséquences économiques et sociales », Archaeologia Mosellana 4, p. 81-184. Dillmann, Philippe, Arandra, Régis, L'Héritier, Maxime \& Fluzin, Philippe, 2005 : « Forging of ironsteel artefacts: archaeology, experiments and archaeometry », dans M. Urteaga (éd.), Iron, History and Heritage. 1st International Conference of Paleosiderurgy and Industrial Heritage Recovery, San Sebastian, p. 311-324.

Dillmann, Philippe, Schwab, Roland, Bauvais, Sylvain, Brauns, Michael, Disser, Alexandre, Leroy, Stéphanie, Gassmann, Guntram \& Fluzin, Philippe, 2017, « Circulation of iron products in the North-Alpine area during the end of the first Iron Age $\left(6^{\text {th }}-5^{\text {th }}\right.$ C. BC): A combination of chemical and isotopic approaches», Journal of Archaeological Science 87, p. 108-124.

Dunikowski, Christophe \& Саввої, Sandra, 1995, La sidérurgie chez les Sénons : les ateliers celtiques et gallo-romains des Clérimois (Yonne), Paris (Documents d'Archéologie Française 51).

Disser, Alexandre, 2014, Production et circulation du fer en Lorraine (VI ${ }^{e}$ s. av. J.-C. - $x V^{e}$ s. ap. J.-C.), Thèse de doctorat, Université de Belfort-Montbéliard.

DubreucQ, Émilie, 2013, Métal des premiers Celtes : productions métalliques sur les habitats des provinces du Hallstatt centre-occidental, Dijon (Art, archéologie et patrimoine).

Filippini, Anne, 2015, La métallurgie du fer dans le centre-est de la France au ve siècle avant J.-C. Approches historique, archéologique et archéométrique, Tours (59e supplément à la Revue archéologique du Centre de la France).

FLouest, Jean-Loup, 2007, «Approches quantitatives de la production de fer sur le site hallstattien de Bragnysur-Saône (Saône-et-Loire) » dans Pierre-Yves Milcent, (éd.), L'économie du fer protohistorique : de la production à la consommation du métal. XXVIIIe colloque AFAEF, Toulouse 20-23 mai 2004, Bordeaux (Aquitania, suppl. $14 / 2)$, p. 265-270.

FronteAu Gilles \& Boyer, François, 2011, « Les géomatériaux meuliers : de l'identification des sources géologiques à la définition de catégories de gisements », dans Olivier Buchsenschutz, Luc Jaccottey, Florent Jodry \& JeanLuc Blanchard (éds), Évolution typologique et technique des meules du Néolithique à l'an mille sur le territoire français. IIIe Rencontres Archéologiques de l'Archéosite gaulois, Bordeaux (Aquitania, suppl. 23), p. 121-135.

Gassmann, Guntram, Rösch, Manfred \& Wieland, Günther, 2006, « Das Neuenbürger Erzrevier im Nordschwarzwald als Wirtschaftsraum während der Späthallstatt- und Frühlatènezeit », Germania 84, p. 273-306.

GASSMANN, Guntram \& Wieland, Günther, 2014, « Frühkeltische Eisenproduktion im Nordschwarzwald: Montanarchäologische Forschungen im Neuenbürger Erzrevier 2004-2011 », dans S. Hornung (éd.), Produktion Distribution - Ökonomie, Siedlungs- und Wirtschaftsmuster der Latènezeit, Akten des internationalen Kolloquiums in Otzenhausen, 28.-30. Oktober 2011, Bonn (Universitätsforschungen zur prähistorischen Archäologie 258), p. 163-170. Gentner, Steeve, 2016, «Économie du fer et voies de communication de l'abattage du minerai à la distribution du métal : I'exemple du nord de la Forêt-Noire au ve siècle avant J.-C. », Archimède 3, p. 150-168.

Hamon, Caroline \& Blanchet, Stéphane, 2015, « Le macro-outillage lithique sur les sites de l'âge du Bronze armoricain : quelques hypothèses fonctionnelles pour aborder la notion d'artisanat », dans Nicolas Théophane \& Sylvie Boulud-Gazo (éd.), Artisanats et productions à l'âge du Bronze, Actes de la journée de la Société Préhistorique Française, Nantes, 2011 (Séance de la Société Préhistorique Française 4), p. 63-82.

JODRY, Florent, 2015, «Étude des enclumes de Neuville-sur-Sarthe-La Chataigneraie », dans Jean-Yves Langlois (éd.), Le bassin sidérurgique du nord du Mans de l'âge du Fer au Moyen Âge. Rapport de fouille, Inrap Grand-Ouest.

Koenig, Marie-Pierre \& LegendRe, Jean-Pierre, 1997, « Une "résidence princière" au Hallstatt D dans la région de Haguenau », dans Patrice Brune \& Bruno Chaume (dir.), Vix et les éphémères principautés celtiques, Actes du Colloque de Chatillon-sur-Seine, Paris (Archéologie Aujourd'hui), p. 83-92.

KuhNLe, Gertrud \& Tesnier-Hermetey, Corinne 2005, « Holtzheim « Am Schluesselberg 》 (Bas-Rhin) : un habitat hallstattien de bord de terrasse loessique dans la plaine du Rhin supérieur », dans Anne-Marie Adam (dir.), Recherches de Protohistoire alsacienne : la céramique d'habitat du Bronze final III à La Tène ancienne, Dijon (23ème supplément à la Revue Archéologique de l'Est), p. 179-209.

Kunnle, Gertrud, dir., 2015, Un deuxième dépôt de demi-produits de fer de l'âge du Fer à Durrenentzen, Rapport de diagnostic archéologique, Inrap Grand Est Sud, Strasbourg.

Labaune, Régis \& Alix, Stéphane, 2014, Talant, Plombières-les Dijon, Côte-d'Or, Bourgogne, Peute Combe, Les Vaux Bruns : découverte d'un établissement rural gallo-romain et d'un hameau à vocation artisanale du ve siècle avant J. C. Rapport de fouilles, Inrap GES, Dijon, 6 vol.

Landolt, Michaël, Van Es, Marieke, Putelat, Olivier, Bouquin, Denis, SchaAl, Caroline \& BoËs, Éric, 2007, Entzheim-Geispolsheim (67) : Aéroparc (Lidl-CUS), les occupations protohistoriques. Rapport de fouille, Pôle d’Archéologie Interdépartemental Rhénan, Sélestat.

LANdolt, Michaël, Abert, Franck, Bolly, Alexandre \& LeProvost, Céline, 2013, Entzheim-Geispolsheim, Bas-Rhin, Lotissement d'activités du quadrant 4, Entzheim «In der Klamm » et Geispolsheim "Schwobenfeld », Rapport de fouille préventive, Pôle d'Archéologie Interdépartemental Rhénan, Sélestat, 6 vol.

Lasserre, Marina, Vigreux, Thomas, Basoge, florian, Logel, Thierry, Putelat, Olivier, Schneider, Nathalie, Michler, Matthieu, Jodry, Florent \& BoËs, Xavier, 2011, « Le site de la fin du Bronze final du Hexenberg à Leutenheim (Bas-Rhin) : études sur le paléoenvironnement rhénan et études archéologiques. Résultats préliminaires », Bulletin de la Société Préhistorique Française 108, p. 731-754.

Latron-Colecchia, Anna Maria, 2015, Quelques indices matériels de la Culture Bischheim occidentale du Rhin supérieur et des témoins d'une activité métallurgique de l'âge du Fer à Kurtzenhouse lotissement Galgenstraenge IV, Rapport de diagnostic archéologique, Inrap, GES, Strasbourg. 
Lefranc, Philippe, BoËs, Éric \& Véber, Cécile, 2008, « Un habitat de La Tène ancienne à Souffelweyersheim «Les Sept Arpents » (Bas-Rhin)», Revue archéologique de I'Est 57, p. 41-74.

Leroy, Marc \& CAвboï, Sandra (dir), 2013, Les formes d'organisation de la production du fer en métallurgie ancienne. Systèmes de production et chaînes opératoires dans les ateliers de l'est du Bassin parisien de l'âge du Fer au haut Moyen Âge, Projet collectif de recherche, SRA Lorraine, Jarville.

LeUvReY, Jean-Michel, 1999, Hauterive-Champréveyres, 12. L'industrie lithique du Bronze final, étude typo-technologique, Neuchâtel (Archéologie neuchâteloise 24).

Mauvilly Michel, Serneels, Vincent, Ruffieux, Mireille \& Garcia-Cristobal, Evencio, 2007, « Le travail du fer dans une forge du milieu du ve siècle av. J.-C. à Sévaz-Tudingues (canton de Fribourg, Suisse) », dans Pierre-Yves Milcent (dir.), L'économie du fer protohistorique : de la production à la consommation du métal, XXVIII colloque AFEAF, Toulouse, 2004, Bordeaux (Aquitania Supplément 14-2), p. 271-278.

Malrain, François, Blancquert, Geertrui \& LoRhi, Thierry, 2013, L'habitat rural du second âge du Fer. Rythmes de création et d'abandon au nord de la Loire, Paris (Recherches Archéologiques 7).

Menez, Yves, Viver Jean-Bernard, Chanson, Karine \& Dupré, Mathilde, 2007, « La forge de Paule (Côtesd'Armor) », dans Pierre Yves Milcent (dir.), L'économie du fer protohistorique : de la production à la consommation du métal, XXVIII colloque AFEAF, Toulouse 2004, Bordeaux (Aquitania Supplément 14-2), p. 213-237.

MÉniel, Patrice, 1993, «La faune des structures de La Tène ancienne de Rosheim « Mittelweg » et « Sandgrube » », dans Christian Jeunesse, Patrice Méniel \& Brigitte Röder (éd.), L'habitat de La Tène ancienne de Rosheim « Mittelweg » (Bas-Rhin). Fouilles 1992, Strasbourg (Monographies d'archéologie alsacienne 1), p. 132-149.

Mentele, Serge, Plouin, Suzanne \& Guillaume, Maxime 2005, « L'habitat hallstattien de Brumath « lotissement Édouard Manet-deuxième tranche » (Bas-Rhin)», dans Anne-Marie Adam (dir.), Recherches de Protohistoire alsacienne : la céramique d'habitat du Bronze final III à La Tène ancienne, Dijon (23e supplément à la Revue Archéologique de l'Est), p. 143-178.

MichleR, Matthieu, 2016, Ensilage et artisanat du fer au Hallstatt D3/La Tène ancienne à Weyersheim, Rapport de fouille, Inrap GES, Strasbourg.

Michler, Matthieu, Jodry, Florent, Badey, Sylvain \& Clerc, Patrick, avec la coll. de BerRANGer, Marion, CABboï, Luisella \& VAN Es, Marieke, à paraître, « La forge hallstattienne de Weyersheim (Bas-Rhin, France) - Hallstatt D3/La Tène ancienne », dans Linda Boutoille, Rebecca Peake (éd.), Le métallurgiste et ses outils : symboliques, fonctions et techniques durant l'âge du Bronze et l'âge du Fer, Actes du colloque UISPP à Belfast, 24-25 juin 2016.

Pieters, Maxence, 2013, Les outils comme traceurs des activités de transformation des métaux ? Supports de frappe, abrasifs et brunissoirs, outils d'aiguisage et outils de broyage, Thèse de doctorat, Université de Bourgogne, Dijon.

Putelat, Olivier, 2007, « La faune », dans Michaël Landolt (dir.), Entzheim-Geispolsheim (Alsace, Bas-Rhin), Aéroparc (LIDL-CUS), Rapport de fouille préventive, vol. 3, Les occupations protohistoriques, Sélestat, Pôle d'Archéologie Interdépartemental Rhénan.

Putelat, Olivier, 2010, «Archéozoologie » dans Carine Deslex \& Philippe Amiot (dir.), Occupations protohistoriques à Chevenez : de l'âge du Bronze à la fin de l'âge du Fer, Porrentruy (Cahier d'archéologie jurassienne 26), p. 52, 77-82, 113-119, 139-153.

Putelat, Olivier, 2015, Les relations homme-animal dans le monde des vivants et des morts. Étude archéozoologique des établissements et des regroupements funéraires ruraux de l'Arc jurassien et de la Plaine d'Alsace, de la fin de I'Antiquité tardive au premier Moyen Âge, Thèse d'archéologie, Université de Paris 1 Panthéon-Sorbonne.

Putelat, Olivier, 2016, « Étude de la faune », dans Michler, Matthieu, Ensilage et artisanat du fer au Hallstatt D3/La Tène ancienne à Weyersheim, 2016, p. 161-179

Putelat, Olivier \& LANdolt, Michaël, 2013, « La caractérisation des dépôts animaux de La Tène ancienne à Geispolsheim Schwobenfeld 》(Bas-Rhin), dans Ginette Auxiette \& Patrice Méniel (dir.), Les dépôts d'ossements d'animaux en France, de la fouille à l'interprétation, Actes de la table-ronde de Bibracte, 15-17 octobre 2012, Montagnac (Archéologie des plantes et des animaux 4), p. 25-68.

ROth-Zehner, Muriel, 2013, « Les établissements ruraux de la fin du Hallstatt et du début de La Tène dans la plaine d'Alsace. État de la question », Cahiers Alsaciens d'Archéologie d'Art et d'Histoire 56, p. 53-87.

Treffort, Jean-Michel \& Dumont, Annie, 2000, Merxheim « Trummelmatten», Néolithique, Bronze final, Hallstatt et haut Moyen Âge, Document final de synthèse de sauvetage urgent, A.F.A.N., Strasbourg.

Vazquez, Patricia, Acuña, Marta, Benavente, David, Gibeaux, Soizic, Navarro, Irene \& GomezHerAs, Miguel, 2016, «Evolution of surface properties of ornamental granitoids exposed to high temperatures », Construction and Building Materials 104, p. 263-275.

VÉbER, Cécile, 2015, Une occupation du Bronze moyen, des silos de La Tène ancienne et un chemin médiéval. Duntzenheim, Bas-Rhin, «Schlittweg, Weingartenberg», LGV EE site 8-2. Rapport de fouilles, Inrap GES, Strasbourg. Zenner, Muriel, 2001, Hatten, zone industrielle, lieu-dit Rothsmatt (Bas-Rhin). Document final de synthèse, fouille de sauvetage urgent, Antea. 